\title{
Anthropogenic emissions during Arctas-A: mean transport characteristics and regional case studies
}

\author{
D. L. Harrigan ${ }^{1,4}$, H. E. Fuelberg ${ }^{1}$, I. J. Simpson ${ }^{2}$, D. R. Blake ${ }^{2}$, G. R. Carmichael $^{3}$, and G. S. Diskin ${ }^{5}$ \\ ${ }^{1}$ Department of Meteorology, Florida State University, Tallahassee, FL, USA \\ ${ }^{2}$ Department of Chemistry, University of California, Irvine, CA, USA \\ ${ }^{3}$ Center for Global and Regional Environmental Research, University of Iowa, Iowa City, IA, USA \\ ${ }^{4}$ National Oceanic and Atmospheric Administration, National Weather Service, Tallahassee, FL, USA \\ ${ }^{5}$ NASA Langley Research Center, Hampton, VA, USA
}

Received: 12 January 2011 - Published in Atmos. Chem. Phys. Discuss.: 15 February 2011

Revised: 11 August 201 - Accepted: 12 August 2011 - Published: 25 August 2011

\begin{abstract}
The National Aeronautics and Space Administration (NASA) conducted the Arctic Research of the Composition of the Troposphere from Aircraft and Satellites (ARCTAS) mission during 2008 as a part of the International Polar Year (IPY). The purpose of ARCTAS was to study the factors responsible for changes in the Arctic's atmospheric composition and climate. A major emphasis was to investigate Arctic haze, which is most pronounced during winter and early spring. This study focuses on the spring phase of ARCTAS (ARCTAS-A) that was based in Alaska during April 2008. Although anthropogenic emissions historically have been associated with Arctic haze, biomass burning emissions dominated the ARCTAS-A period and have been the focus of many ARCTAS related studies.

This study determines mean transport characteristics of anthropogenic emissions during ARCTAS-A. Trajectories are initiated each day from three significant regions of anthropogenic emissions (Asia, North America, and Europe). The fifteen day forward trajectories are calculated using data from the Weather Research and Forecasting (WRF) model at $45 \mathrm{~km}$ horizontal resolution. The trajectory calculations indicate: origins of emissions that reach the Arctic (defined as north of $70^{\circ} \mathrm{N}$ ) within fifteen days, pathways of these emissions, Arctic entry locations, and altitudes at which the trajectories enter the Arctic.

Three cases during the ARCTAS-A period (one for each of the regions above) are examined using backward trajectories and chemical fingerprinting based on in situ data sampled from the NASA DC-8. The fingerprinting utilizes volatile
\end{abstract}

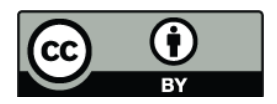

Correspondence to: H. E. Fuelberg (hfuelberg@fsu.edu) organic compounds that represent pure anthropogenic tracers, Asian anthropogenic pollution, incomplete combustion, and natural gas emissions. We determine flight legs containing anthropogenic emissions and the pathways travelled by these emissions. Results show that the DC- 8 sampled anthropogenic emissions from Asia, North America, and Europe during the spring phase of ARCTAS. The pathways travelled by these emissions agree with our derived transport characteristics and previous studies of Arctic transport. Meteorological analysis and trajectory calculations indicate that middle latitude cyclones and their associated warm conveyor belts play an important role in lofting the surface based emissions to their sampling altitude in all three cases.

\section{Introduction}

Since the Arctic is far removed from most industrial locations and other sources of pollution, its atmosphere once was believed to be very clean. However, parts of the Arctic actually can become very polluted due to the transport of emissions from distant sources (Raatz and Shaw, 1984; Shaw, 1995; Rinke et al., 2004). There also are pollution sources within the Arctic from natural gas and oil extraction and other heavy industry. The greatest concentrations of Arctic pollution occur during the winter and early spring months (Mitchell, 1957; Shaw, 1995; Eckhardt et al., 2003). The buildup of pollutants during these months, combined with photochemical reactions (beginning in early spring), produce a visibility reducing haze called "Arctic Haze" (Mitchell, 1957; Shaw, 1983; Hileman, 1983; Schnell, 1984; Meyer et al., 1990). This phenomenon first was documented during the 1950's by Air Force pilots during weather reconnaissance flights

Published by Copernicus Publications on behalf of the European Geosciences Union. 
(Mitchell, 1957). The haze typically is most concentrated near the surface, with discontinuous horizontal layers in the middle and upper troposphere (Hileman, 1983; Hoff, 1987).

Arctic haze long was considered to consist mostly of anthropogenic pollutants (Hileman, 1983; Barrie and Hoff, 1985; Barrie et al., 1994), with primary species being a mixture of sulfates and particulate organic matter ( $\mathrm{Li}$ and Barrie, 1993; Quinn et al., 2002). Other species include ammonium, nitrate, dust and black carbon ( $\mathrm{Li}$ and Barrie, 1993; Quinn et al., 2002). Shaw (1995) noted that heavy metals detected in the haze are associated with industrial sources. Recent research has shown that boreal forest fires in Siberia and eastern China, as well as agricultural burning in Kazakhstan, southern Russia, and eastern Europe also are important sources of Arctic pollution (Warneke et al., 2009, 2010). This source of biomass burning emissions may increase in the future due to the effects of climate change (e.g., Kasischke et al., 2005; Wotton et al., 2010).

Several factors contribute to the buildup of pollutants in the Arctic atmosphere. First, the Arctic atmosphere is dominated by strong temperature inversions that trap air near the surface, especially during the winter and early spring when there is little or no sunlight (Curry, 1983, 1987; Raatz, 1991; Bradley et al., 1992). Since these inversions limit turbulent mixing, dry deposition is greatly reduced (Hileman, 1983). Furthermore, since the atmosphere during the winter and early spring is cold, dry, and stable, precipitating cloud systems are inhibited, thereby also limiting wet deposition (Shaw, 1995). Another phenomenon that influences cold season Arctic transport is the "dome" of cold potential temperature that forms over the polar region (Klonecki et al., 2003; Stohl, 2006; Law and Stohl, 2007). Since potential temperature increases with altitude in the stable atmosphere, and due to the temperature difference between the middle latitudes and the Arctic, the potential temperature (isentropic) surfaces curve upward from the mid latitudes to the Arctic (Carlson, 1981; Iverson, 1984; Raatz, 1991). If one assumes adiabatic conditions, low level trajectories moving northward from the middle latitudes must ascend as they approach the Arctic. Conversely, for trajectories to remain near the surface while heading poleward, they must be diabatically cooled by radiative effects such as passing over snow and ice.

Three typical transport pathways to the Arctic during the winter months have been identified by Stohl (2006). The first consists of rapid low level transport of already cold air north of the Arctic Front. A variation of this scenario is the rapid northward transport of air originally south of the Arctic front up and over the Arctic Front. The second method of transport occurs on a longer time scale in which cold air is transported over a snow covered surface, allowing it to cool sufficiently to penetrate the Arctic isentropic dome. Finally, middle latitude air can be lofted into the upper troposphere and then quickly transported to the Arctic where it gradually sinks into the lower troposphere due to radiative cooling. These three transport processes generally mean that European emissions are the dominant source of pollutants in the low levels of the Arctic atmosphere, while North American and east Asian pollutants are more common in the middle and upper levels (Klonecki et al., 2003; Stohl, 2006; Law and Stohl, 2007).

The National Aeronautics and Space Administration (NASA) conducted the Arctic Research of the Composition of the Troposphere from Aircraft and Satellites (ARCTAS) field mission during 2008 (Jacob et al., 2010). ARCTAS was conducted primarily over the Arctic areas of Alaska, Canada, and Greenland and was a component of the Polar Study using Aircraft, Remote Sensing, Surface Measurements and Models of Climate, Chemistry, Aerosols and Transport (POLARCAT, Stohl and Law, 2006). ARCTAS consisted of two deployments, one based in Alaska (April 2008) and the other in Alberta, Canada (June-July 2008). The main goal of ARCTAS was to better understand the factors that contribute to changes in the composition of the Arctic atmosphere and climate by studying the influx of mid-latitude pollutants, boreal forest fire emissions, aerosol radiative forcing, and chemical processes (Jacob et al., 2010).

Anthropogenic emissions were expected to dominate the Arctic atmosphere during the spring phase of ARCTAS (hereafter denoted ARCTAS-A). However, that did not occur. Instead, widespread fires in Russia were the major source of Arctic pollution during the period (Warneke et al., 2009; Jacob et al., 2010). The fires started unusually early, consisting of agricultural burning in Kazakhstan and southern Russia as well as boreal forest fires in Siberia (Warneke et al., 2009). ARCTAS related research has examined the sources and characteristics of the biomass burning emissions (e.g., Kondo et al., 2011; Matsui et al., 2011; Oltmans et al., 2010; Singh et al., 2010). Although biomass burning emissions were the dominant source of Arctic pollution during ARCTAS-A, our focus is the characteristics and transport pathways of anthropogenic emissions to the Arctic during the spring period. We utilize in situ chemical data sampled from the NASA DC-8 flying laboratory and backward kinematic trajectories derived from high resolution numerical modeling to identify source regions of the anthropogenic emissions that were sampled by the aircraft. Three specific cases are examined, one for each of the major source regions (Europe, Asia, and North America).

Section 2 provides details about the meteorological numerical model that we employed as well as the trajectory products derived from its output. Information about other methodologies and the specifics of our various data sources also is provided. Sections 3-8 present derived ARCTAS-A transport characteristics for each of the three major source regions as well as results from the three cases of anthropogenic Arctic transport. 


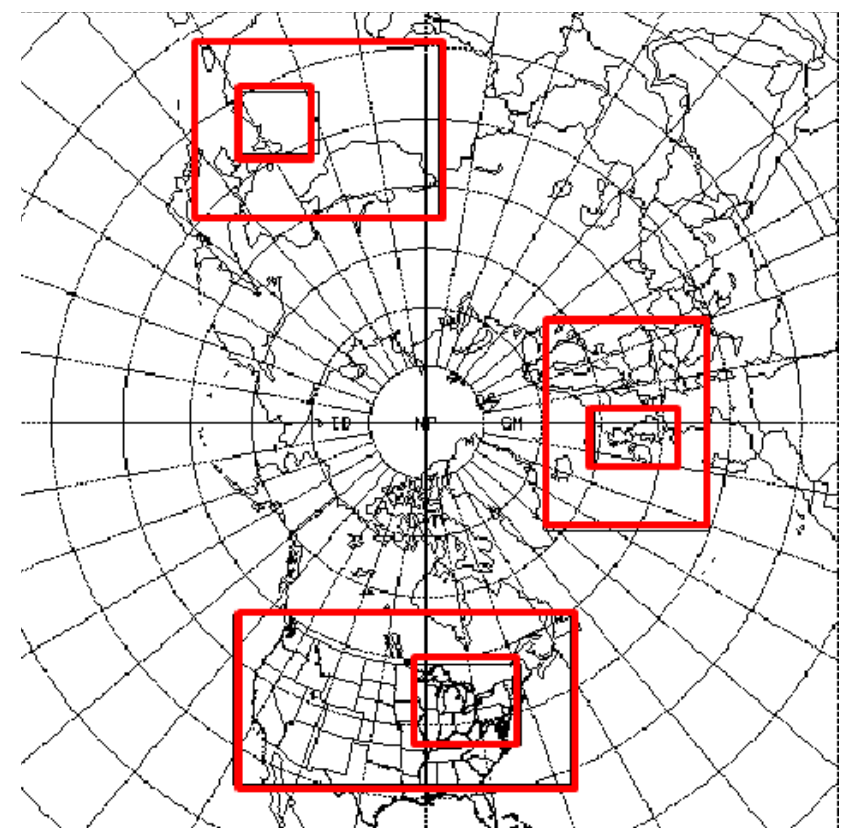

Fig. 1. Parent domain (45 km, black) and inner nests $(15 \mathrm{~km}$ and $5 \mathrm{~km}$, red) used for the ARCTAS simulations.

\section{Data and methodology}

\subsection{WRF Model}

Numerical simulations were used to study weather patterns responsible for transport to the Arctic (defined as the region north of $70^{\circ} \mathrm{N}$ ) during the ARCTAS mission. This study utilized the Weather Research and Forecast (WRF) model (Skamarock et al., 2008) version 3.0.1.1 developed by the National Center for Atmospheric Research (NCAR). We chose WRF instead of the Global Forecast System (GFS) since the latter is available at only $0.5^{\circ} \times 0.5^{\circ}$ horizontal resolution and at a coarser temporal resolution. Our WRF parent domain had a $45 \mathrm{~km}$ horizontal resolution centered on the North Pole (Fig. 1). It was important to resolve areas of greatest anthropogenic emissions at the highest resolution that our computing facilities would allow. Therefore, we placed inner telescoping nests of 15 and $5 \mathrm{~km}$ centered over three major anthropogenic source regions including Europe, eastern Asia, and North America. These inner nests provided twoway feedback to the coarse grid. The parent domain and each of the inner nests consisted of 50 vertical sigma levels that were packed in the boundary layer and near the tropopause. The specific physics packages used in our WRF simulations are listed in Table 1 and Fuelberg et al. (2010). Detailed discussions about each of the settings in Table 1 can be found in Skamarock et al. (2008). The model was initialized with final analysis data from the Global Forecast System (GFS) at $0.5^{\circ} \times 0.5^{\circ}$ horizontal resolution. GFS is run operationally by the National Center for Environmental Prediction (available at http://www.nco.ncep.noaa.gov/pmb/products/).
Table 1. WRF physics options used in this study. See Skamarock et al. (2008) for details about each option.

\begin{tabular}{ll}
\hline Option & Setting \\
\hline Microphysics & Morrison Double-Moment \\
Longwave Radiation & Rapid Radiative Transfer Model \\
Shortwave Radiation & Goddard \\
Surface Layer & ETA Similarity \\
Land Surface & NOAH \\
Boundary Layer & Mellor-Yamada-Janjic \\
Cumulus Parameterization & Kain-Fritsch \\
\hline
\end{tabular}

\subsection{Trajectory calculations}

Trajectories represent the paths taken by air parcels over a period of time. Our three dimensional kinematic trajectories were calculated using $\mathrm{u}, \mathrm{v}$, and $\mathrm{w}$ wind components from the WRF hourly data at $45 \mathrm{~km}$ resolution. Although the 15 and $5 \mathrm{~km}$ nested data were not used explicitly, the nesting did influence the $45 \mathrm{~km}$ parent grid through two way interactions. Additional details about our trajectory model are given in $\mathrm{Fu}-$ elberg et al. (1996, 2000) and Martin et al. (2002). If a trajectory intersected the lower boundary, it was continued isobarically along the surface and possibly lofted later by vertical motion, a procedure similar to Stohl et al. (1995). Limitations of trajectories are described in Stohl et al. $(1995,1998)$ and Fuelberg et al. (2000).

Fuelberg et al. (2010) used forward trajectories to describe overall northern hemispheric transport to the Arctic during ARCTAS. In the current study we describe transport characteristics for three specific regions of interest (Europe, Asia, and North America). To facilitate easy comparisons between the two studies, we employ the same meteorological model, grid nesting, and trajectory methodology as Fuelberg et al. (2010). We used a Lagrangian particle dispersion model (LPDM) (FLEXPART, Stohl, 2005) as a preliminary tool to help select the three individual case studies. Specifically, we looked for flights when plumes of anthropogenic $\mathrm{CO}$ from FLEXPART intersected the flight tracks. We then determined the particular leg of the flight when this occurred and began to analyze the chemistry and use trajectories to further explore the meteorology. Although a backward LPDM approach could have been used, we thought that its results were more difficult to interpret and explain than those from backward trajectories. In any event, Fuelberg et al. (2010) present results from both trajectories and the Lagrangian approach, and we are confident that use of a Lagrangian approach would not change any of our current conclusions.

Anthropogenic $\mathrm{CO}$ emissions data from the University of Iowa Center for Global and Regional Environmental Research (CGRER) were used to define the starting locations of fifteen day forward trajectory calculations in our three 

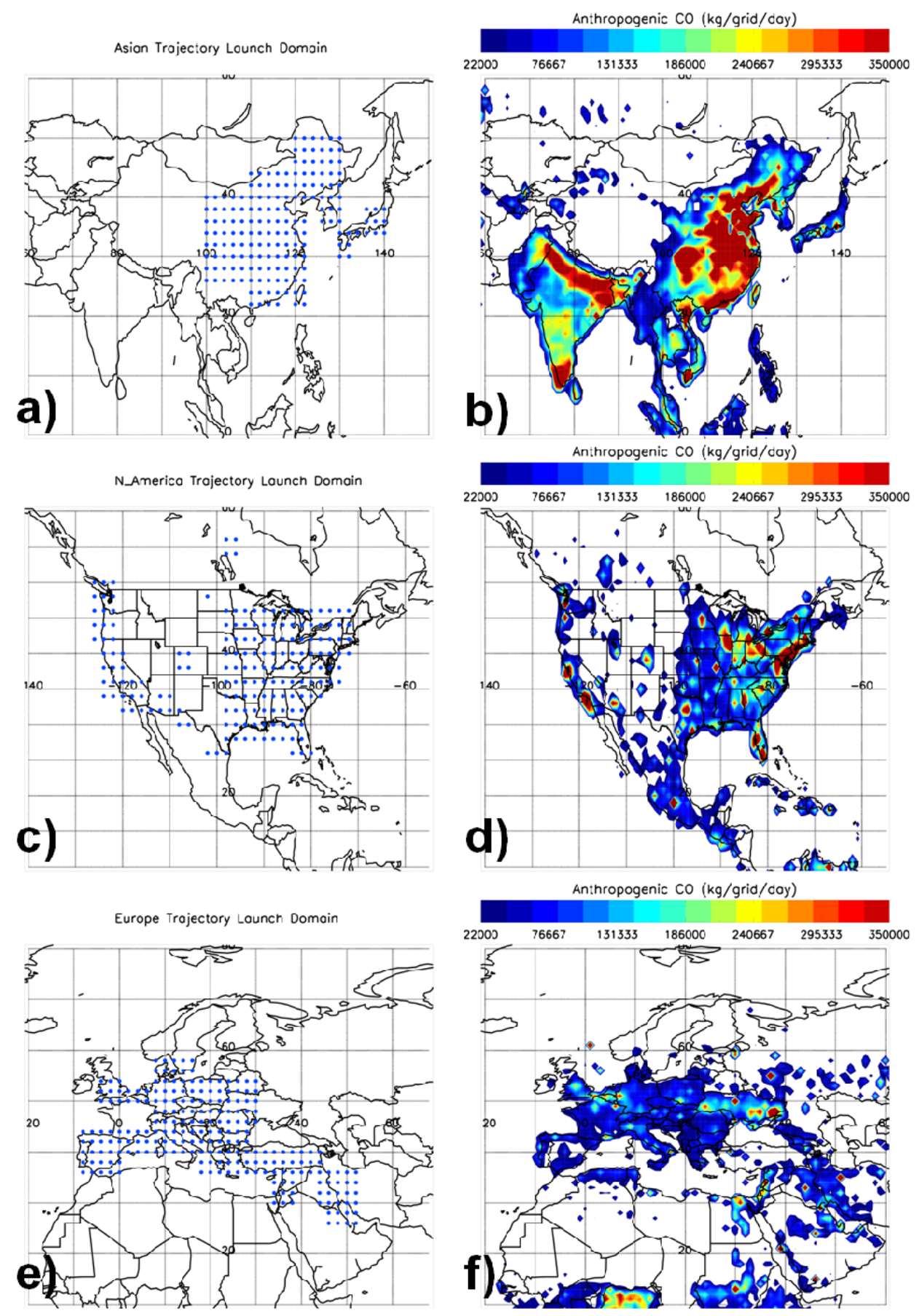

Fig. 2. Trajectory release locations on the $2.0^{\circ} \times 2.0^{\circ}$ grid (blue dots) for (a) Asia,(c) North America, and (e) Europe. These locations were based on anthropogenic emissions during ARCTAS (kg grid point ${ }^{-1}$ day $^{-1}$ ) for (b) Asia, (d) North America, and (f) Europe from the CGRER data set.

regions of emissions (Fig. 2). The CGRER emissions data had been prepared to support the ARCTAS mission (for further information and data access, see http://www.cgrer. uiowa.edu/arctas/emission.html). Specifically, the trajectories were initialized at the surface on a $2.0^{\circ} \times 2.0^{\circ}$ grid within the areas of enhanced emissions. There was a degree of subjectivity in selecting the starting locations. For example, some offshore locations were included if they were close to strong onshore emissions (e.g., the west coast of the US) or areas of major offshore drilling (northern Gulf of Mexico) . 
DC-8 Flight Trock 5 April 2008: Flight 5

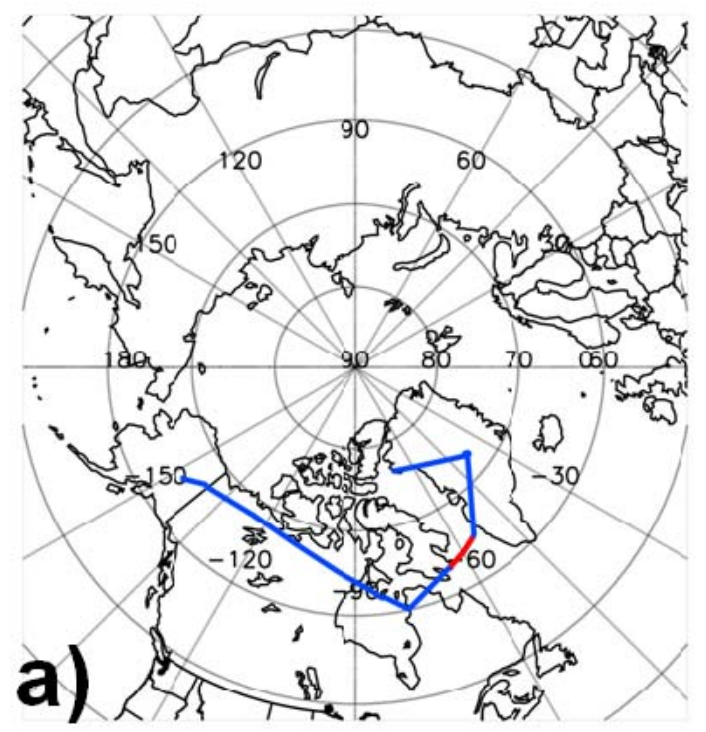

DC-8 Flight Trock 12 April 2008: Flight 8

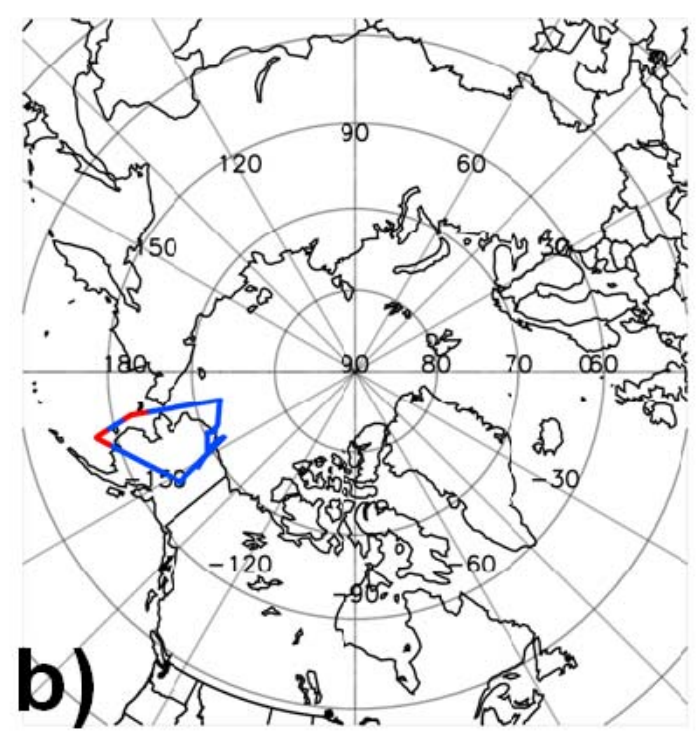

Fig. 3. DC-8 flight tracks for (a) Flight 5 on 5 April 2008, and (b) Flight 8 on 12 April 2008. Trajectories were released at 1 min intervals along the red segments.

Although locations south of our domain (Fig. 1) could not be included, emissions from those distant locations likely would not be significant contributors to the Arctic within the 15 day computational period.

To derive general transport statistics during ARCTAS-A, fifteen day forward trajectories were initialized within the domains of each of the areas of enhanced anthropogenic emissions described in the previous paragraph. Releases were made from the surface each day (14:00 LDT), during the period 19 March through 17 April 2008, with data for the final day of trajectories extending to 3 May 2008. We chose 14:00 LDT because it is near the time of maximum surface temperatures and when the planetary boundary layer often is deepest and turbulent mixing (parameterized in WRF) generally is most pronounced. It is when surface based emissions are most likely to be carried to higher altitudes where the winds are stronger and the trajectories are more likely to reach the Arctic within 15 days.

Backward trajectories for the three case studies were calculated using the same trajectory model described above and using the same WRF-derived wind data. The trajectories were released at $1 \mathrm{~min}$ intervals along specific legs of DC-8 flights 5 and 8 (Fig. 3). At a typical aircraft ground speed of $400 \mathrm{kt}\left(206 \mathrm{~m} \mathrm{~s}^{-1}\right)$ in the upper troposphere, the $1 \mathrm{~min}$ separation corresponds to a distance of $12.4 \mathrm{~km}$. A typical ground speed of $250 \mathrm{kt}\left(130 \mathrm{~m} \mathrm{~s}^{-1}\right)$ in the lower troposphere corresponds to a separation distance of $7.8 \mathrm{~km}$. The trajectories extended 15 days backward in time. Each flight was broken into multiple legs (or segments) based on the pressure level of the flight. Four predetermined altitude blocks were used; when the flight was below $850 \mathrm{hPa}$, between 850 $500 \mathrm{hPa}$, between $500-300 \mathrm{hPa}$, and above $300 \mathrm{hPa}$. Each time the flight entered a new altitude block, a new leg was defined. This allowed us to break the flight into segments, thus reducing the flight data to more manageable increments (more information can be found at http://fuelberg.met.fsu. edu/research/arctas/traj/traj.html).

\subsection{Determining warm conveyor belts}

A WCB is an airstream ahead of a surface cold front that originates near the surface of a cyclone's warm sector and then ascends to the upper troposphere (e.g., Eckhardt et al., 2004). Warm conveyor belts play an integral role in transporting boundary layer air into the upper levels of the atmosphere where it can undergo subsequent long range transport (Ding et al., 2009). WCBs most commonly originate along the east coasts of North America and Asia and are more frequent during winter than summer (Stohl, 2001; Eckhardt et al., 2004). Based on a $15 \mathrm{yr}$ climatology, Eckhardt et al. (2004) determined the timescale of WCBs to be $\sim 2$ days. They classified "reasonably strong" WCBs based on trajectories that, during a 2 day time period, ascended $60 \%$ of the tropopause height and moved eastward at least $10^{\circ}$ longitude and northward at least $5^{\circ}$ latitude. Eckhardt et al. (2004) also noted that most of the moisture at the start of a WCB is converted to precipitation, thereby producing decreased humidity and an increase in potential temperature. The potential temperatures of their trajectories undergoing WCB processes increased $15-22 \mathrm{~K}$ within a $48 \mathrm{~h}$ period. We used these criteria as guidelines in determining whether WCBs played a role in Arctic transport during our case study period. 
Table 2. Atmospheric lifetime, analytical details, and measurement statistics for selected compounds measured in the Asian plume. ARCTAS-A background averages also are included (see text for details).

\begin{tabular}{|c|c|c|c|c|c|c|c|c|c|c|c|}
\hline Compound & Formula & Lifetime & $\begin{array}{r}\text { LOD } \\
(p p t v)\end{array}$ & $\begin{array}{r}\text { Precision } \\
(\%)\end{array}$ & $\begin{array}{r}\text { Accuracy } \\
(\%)\end{array}$ & $\begin{array}{r}\text { Bkgd. Avg } \\
\text { (pptv) }\end{array}$ & $\begin{array}{r}\text { Bkgd. St. } \\
\text { Dev. (pptv) }\end{array}$ & $\begin{array}{l}\text { Asian Plume } \\
\text { Avg. (pptv) }\end{array}$ & $\begin{array}{r}\text { Asian Plume } \\
\text { St. Dev. (pptv) }\end{array}$ & $\begin{array}{r}\text { Enhancement } \\
\text { over average } \\
\text { background } \\
(\%)\end{array}$ & $\begin{array}{r}\text { Asian Plume } \\
\text { Max (pptv) }\end{array}$ \\
\hline 1,2-Dichloroethane & $\mathrm{C}_{2} \mathrm{H}_{4} \mathrm{Cl}_{2}$ & $1-2 \mathrm{mo}$ & 0.1 & 5 & 10 & 11.0 & 0.8 & 57 & 9 & 420 & 64 \\
\hline Methyl chloride & $\mathrm{CH}_{3} \mathrm{Cl}$ & $1.0 \mathrm{yr}$ & 50 & 5 & 10 & 567 & 7 & 739 & 19 & 30 & 751 \\
\hline Halon-1211 & $\mathrm{CBrClF}_{2}$ & $16 \mathrm{yr}$ & 0.1 & 1 & 5 & 4.20 & 0.04 & 4.49 & 0.06 & 7 & 4.55 \\
\hline Carbonyl sulfide & OCS & $2.5 \mathrm{yr}$ & 10 & 2 & 10 & 487 & 4 & 615 & 16 & 26 & 629 \\
\hline Tetrachloroethene & $\mathrm{C}_{2} \mathrm{Cl}_{4}$ & $2-3 \mathrm{mo}$ & 0.01 & 5 & 10 & 4.20 & 0.60 & 6.77 & 0.35 & 61 & 6.99 \\
\hline HCFC-22 & $\mathrm{CHF}_{2} \mathrm{Cl}$ & $12 \mathrm{yr}$ & 2 & 5 & 5 & 195 & 2 & 211.3 & 1.0 & 8 & 212.3 \\
\hline
\end{tabular}

Table 3. As in Table 2, but for the North American plume.

\begin{tabular}{|c|c|c|c|c|c|c|c|c|c|c|c|}
\hline Compound & Formula & Lifetime & $\begin{array}{r}\text { LOD } \\
\text { (pptv) }\end{array}$ & $\begin{array}{r}\text { Precision } \\
(\%)\end{array}$ & $\begin{array}{r}\text { Accuracy } \\
(\%)\end{array}$ & $\begin{array}{l}\text { Bkgd. Avg. } \\
\text { Dev. (pptv) }\end{array}$ & $\begin{array}{r}\text { Bkgd. St. } \\
\text { (pptv) }\end{array}$ & $\begin{array}{r}\text { North American } \\
\text { Plume Avg. } \\
\text { (pptv) }\end{array}$ & $\begin{array}{r}\text { North American } \\
\text { St. Dev. } \\
(\text { pptv })\end{array}$ & $\begin{array}{r}\text { Enhancement } \\
\text { over average } \\
\text { background } \\
(\%)\end{array}$ & $\begin{array}{r}\text { North American } \\
\text { Plume Max } \\
(\mathrm{pptv})\end{array}$ \\
\hline Ethane & $\mathrm{C}_{2} \mathrm{H}_{6}$ & $47 d$ & 3 & 1 & 5 & 1408 & 166 & 1932 & 225 & 37 & 2317 \\
\hline Propane & $\mathrm{C}_{3} \mathrm{H}_{8}$ & $11 \mathrm{~d}$ & 3 & 2 & 5 & 312 & 59 & 573 & 122 & 83 & 798 \\
\hline Benzene & $\mathrm{C}_{6} \mathrm{H}_{6}$ & $9 \mathrm{~d}$ & 3 & 3 & 5 & 49 & 12 & 86 & 13 & 76 & 103 \\
\hline HCFC-22 & $\mathrm{CHF}_{2} \mathrm{Cl}$ & $12 \mathrm{yr}$ & 2 & 5 & 5 & 195 & 2 & 201 & 4 & 3 & 210 \\
\hline Tetrachloro ethene & $\mathrm{C}_{2} \mathrm{Cl} 4$ & $2-3 \mathrm{mo}$ & 0.01 & 5 & 10 & 4.20 & 0.60 & 6.35 & 1.36 & 51 & 8.29 \\
\hline
\end{tabular}

\subsection{Chemical data}

Chemical data used in this study were collected by two groups aboard the NASA DC-8 during the ARCTAS campaign. The University of California-Irvine (UCI) atmospheric chemistry group used whole air sampling (WAS) techniques to measure 76 speciated volatile organic compounds (VOCs) (Simpson et al., 2010), and NASA Langley used the DACOM instrument to measure methane $\left(\mathrm{CH}_{4}\right)$ and carbon monoxide (CO) (Sachse et al., 1987; Anderson et al., 1996; Blake et al., 1996). We used these data to identify anthropogenic emissions and tag their respective source regions. In particular we used carbonyl sulfide (OCS), halon-1211 (H-1211), methyl chloride $\left(\mathrm{CH}_{3} \mathrm{Cl}\right)$ and 1,2dichlorethene (1,2-DCE) as tracers of Asian anthropogenic pollution plumes (Barletta et al., 2009); ethyne $\left(\mathrm{C}_{2} \mathrm{H}_{2}\right)$ and benzene $\left(\mathrm{C}_{6} \mathrm{H}_{6}\right)$ as tracers of incomplete combustion, including biomass burning and/or urban fossil fuel (Blake et al., 2003; Warneke et al., 2007); methane $\left(\mathrm{CH}_{4}\right)$, ethane $\left(\mathrm{C}_{2} \mathrm{H}_{6}\right)$ and propane $\left(\mathrm{C}_{3} \mathrm{H}_{8}\right)$ as probes for natural gas (Katzenstein et al., 2003; Xiao et al., 2008); and tetrachloroethene $\left(\mathrm{C}_{2} \mathrm{Cl}_{4}\right)$ and HCFC-22 as purely anthropogenic tracers since they have no known natural sources (Aucott et al., 1999; Simpson et al., 2004).

Measurements of $\mathrm{CO}$ and $\mathrm{CH}_{4}$ using the DACOM diode laser absorption instrument were made with $1 \mathrm{~s}$ temporal resolution during the entire ARCTAS campaign, except for brief periodic calibration intervals. The DACOM measurements were averaged to the sampling period of the WAS instrument for this study. Details about the DACOM instru- ment can be found in Sachse et al. (1987, 1988). Specific information about the WAS sampling techniques and processing of these data can be found in Blake (2008), Simpson et al. (2010), and the references therein. Briefly, 168 whole air canisters were loaded on the DC-8 prior to each flight, and were filled sequentially throughout the flight. Sampling times typically were 1 min during horizontal flight legs, and $30 \mathrm{~s}$ to 1 min during ascents and descents. Because of the finite number of canisters, samples generally were taken every 4-5 min, and more frequently during ascents, descents, and plume encounters. The detection limit, precision and accuracy of the measurements vary by compound, and are shown for the 10 species that we considered in Tables 2, 3 , and 4 of the results section. These 10 compounds have a range of atmospheric lifetimes, from 9 days (benzene) to $16 \mathrm{yr}$ (H-1211) (Tables 2, 3, and 4). Since trace gases undergo chemistry and mixing as soon as they are released from their emission source, a short-lived gas such as benzene will become relatively more depleted during its multi-day transit from its emission source to the DC-8 sampling location. Therefore, our identification of anthropogenic plumes from specific emission source regions was based on a combination of chemical fingerprinting and back trajectory analysis, rather than by attempting to compare the measured data to known emission ratios from specific sources, which requires relatively fresh plumes to be sampled (minutes to hours old).

An additional consideration in the analysis is that many of the trace gases being examined vary with time (diurnally, seasonally, and annually) and space (latitudinally and altitudinally). For example HCFC-22 is experiencing rapid 
Table 4. As in Table 2, but for the European plume.

\begin{tabular}{|c|c|c|c|c|c|c|c|c|c|c|c|}
\hline Compound & Formula & Lifetime & $\begin{array}{r}\text { LOD } \\
(\mathrm{pptv})\end{array}$ & $\begin{array}{r}\text { Precision } \\
(\%)\end{array}$ & $\begin{array}{r}\text { Accuracy } \\
(\%)\end{array}$ & $\begin{array}{r}\text { Bkgd. Avg } \\
\text { (pptv) }\end{array}$ & $\begin{array}{r}\text { Bkgd. St. } \\
\text { Dev. (pptv) }\end{array}$ & $\begin{array}{r}\text { European Plume } \\
\text { Avg. (pptv) }\end{array}$ & $\begin{array}{r}\text { European St. } \\
\text { Dev. (pptv) }\end{array}$ & $\begin{array}{r}\text { Enhancement } \\
\text { over average } \\
\text { background } \\
(\%)\end{array}$ & $\begin{array}{r}\text { European Plume } \\
\text { Max (pptv) }\end{array}$ \\
\hline Tetrachloroethene & $\mathrm{C}_{2} \mathrm{Cl}_{4}$ & $2-3 \mathrm{mo}$ & 0.01 & 5 & 10 & 4.20 & 0.60 & 6.03 & 0.86 & 44 & 6.93 \\
\hline Ethyne $\mathrm{C}_{2} \mathrm{H}_{2}$ & $12-17 \mathrm{~d}$ & 3 & 3 & 5 & 264 & 42 & 519 & 79 & 97 & 600 & \\
\hline Benzene & $\mathrm{C}_{6} \mathrm{H}_{6}$ & $9 \mathrm{~d}$ & 3 & 3 & 5 & 49 & 12 & 112 & 17 & 129 & 131 \\
\hline Methane (ppbv) & $\mathrm{CH}_{4}$ & $9 \mathrm{yr}$ & $\mathrm{n} / \mathrm{a}$ & 0.1 & 1 & $1840^{*}$ & $8^{*}$ & $1871^{*}$ & $8^{*}$ & 2 & $1877^{*}$ \\
\hline Ethane & $\mathrm{C}_{2} \mathrm{H}_{6}$ & $47 \mathrm{~d}$ & 3 & 1 & 5 & 1408 & 166 & 1917 & 47 & 36 & 1972 \\
\hline Propane & $\mathrm{C}_{3} \mathrm{H}_{8}$ & $11 \mathrm{~d}$ & 3 & 2 & 5 & 312 & 59 & 537 & 36 & 72 & 577 \\
\hline
\end{tabular}

* Asterisks for $\mathrm{CH}_{4}$ denote that its units are ppbv instead of pptv.

year-to-year growth (Montzka et al., 2009), whereas global $\mathrm{C}_{2} \mathrm{Cl}_{4}$ levels are continuing a long-term decline (Simpson et al., 2004). Therefore, we calculated a local background for each compound that is appropriate for the season and latitudes that were sampled during ARCTAS-A. Specifically, data from DC-8 flights 4-10 were used (this excludes flights 3 and 11, which were transit flights between Palmdale, CA and Fairbanks, AK). Stratospheric data were removed by choosing a cutoff of $\mathrm{O}_{3}>100$ ppbv. Furthermore, $\mathrm{O}_{3}$ depletion episodes at low altitudes were removed by choosing a cutoff of $\mathrm{O}_{3}<45 \mathrm{ppbv}$. These criteria removed 338 of 1126 data points, leaving 788 points. The background average for each compound then was calculated using the lowest quartile $(25 \%)$ of the remaining data $(n=197)$. These local background averages were compared to the plume enhancements.

\section{Eastern asian transport during ARCTAS-A}

To identify the Arctic bound transport pathways specific to eastern Asia (as defined in Fig. 2a), 15 day forward trajectories were calculated from the WRF model data. During the period 19 March through 17 April 2008, trajectories were initiated each day from the 173 grid points in the Asian domain (Fig. 2a). This region corresponds closely to our $15 \mathrm{~km}$ middle grid nest (Fig. 1). Although the finer $5 \mathrm{~km}$ innermost nest does not include the entire launch area, it does encompass the region of greatest emissions. As noted earlier, both of the nests interact with the parent grid at $45 \mathrm{~km}$ resolution. The result was a total of 5363 releases during the 31 day period. After the trajectories were calculated, their information was combined to determine (1) the number of trajectories (per release grid point) that reached the Arctic (crossed $70^{\circ} \mathrm{N}$ ) within the 15 day period; (2) the common pathways taken by these trajectories; (3) common Arctic entry locations along the $70^{\circ} \mathrm{N}$ latitude belt; (4) and the pressure level at which the trajectories entered the Arctic. Since trajectory uncertainty increases with time after initialization, we focus on large scale trajectory patterns, not the details of individual trajectories.
Figure 4a shows the origins of Asian trajectories that enter the Arctic during ARCTAS-A. In general, trajectories released farther north have a greater chance of being transported to the Arctic within 15 days, while some locations in the southern portion of the domain fail to produce any Arctic bound trajectories. Within the Asian domain, $40 \%$ of the 528 Arctic bound trajectories originated at latitudes greater than $40^{\circ} \mathrm{N}, 55 \%$ came from the region between $30^{\circ} \mathrm{N}$ and $40^{\circ} \mathrm{N}$, and only $5 \%$ originated further south than $30^{\circ} \mathrm{N}$.

To determine the pathways taken by trajectories crossing $70^{\circ} \mathrm{N}$, the hourly position of each trajectory that reached the Arctic was plotted. Figure $4 \mathrm{~b}$ shows the results at $1^{\circ} \times 1^{\circ}$ resolution. Once a trajectory entered the Arctic, it was no longer tracked, even though it could have exited and subsequently re-entered the Arctic at a later time. Thus, only the first occurrence of Arctic entry was recorded. We did not consider the residence time of trajectories after entering the Arctic. Segments of grid points containing the most trajectory passages (the red areas) can be interpreted as important transport pathways. Thus, most trajectories initiated over Asia travel eastward, extending across eastern Siberia and the North Pacific Ocean, over the Bering Sea, northward across western Alaska, and into the Arctic. A smaller number of trajectories pass over western Canada and the central United States.

The aforementioned primary pathway is reflected in the plot of Arctic entry locations (Fig. 4c), where each colored circle represents an entry region that is $5^{\circ}$ longitude wide. The most common Arctic entry location from eastern Asia is along the extreme northeastern part of Siberia, eastward through the Chukchi Sea, and along northwestern and northcentral Alaska. In fact, $62 \%$ of the trajectories that reach the Arctic enter between $180-140^{\circ} \mathrm{W}$. Very few Asian trajectories enter the Arctic from the northeastern Atlantic Ocean and locations eastward through western and central Russia.

The most common Arctic arrival pressures for Asian trajectories are in the middle $(850-500 \mathrm{hPa})$ and upper (less than $500 \mathrm{hPa}$ ) troposphere (Fig. $4 \mathrm{~d}$ ). Only $3 \%$ of the trajectories reaching the Arctic do so in the lower troposphere (greater than $850 \mathrm{hPa}$ ), while $41 \%$ arrive in the middle troposphere and $56 \%$ arrive in the upper troposphere. 

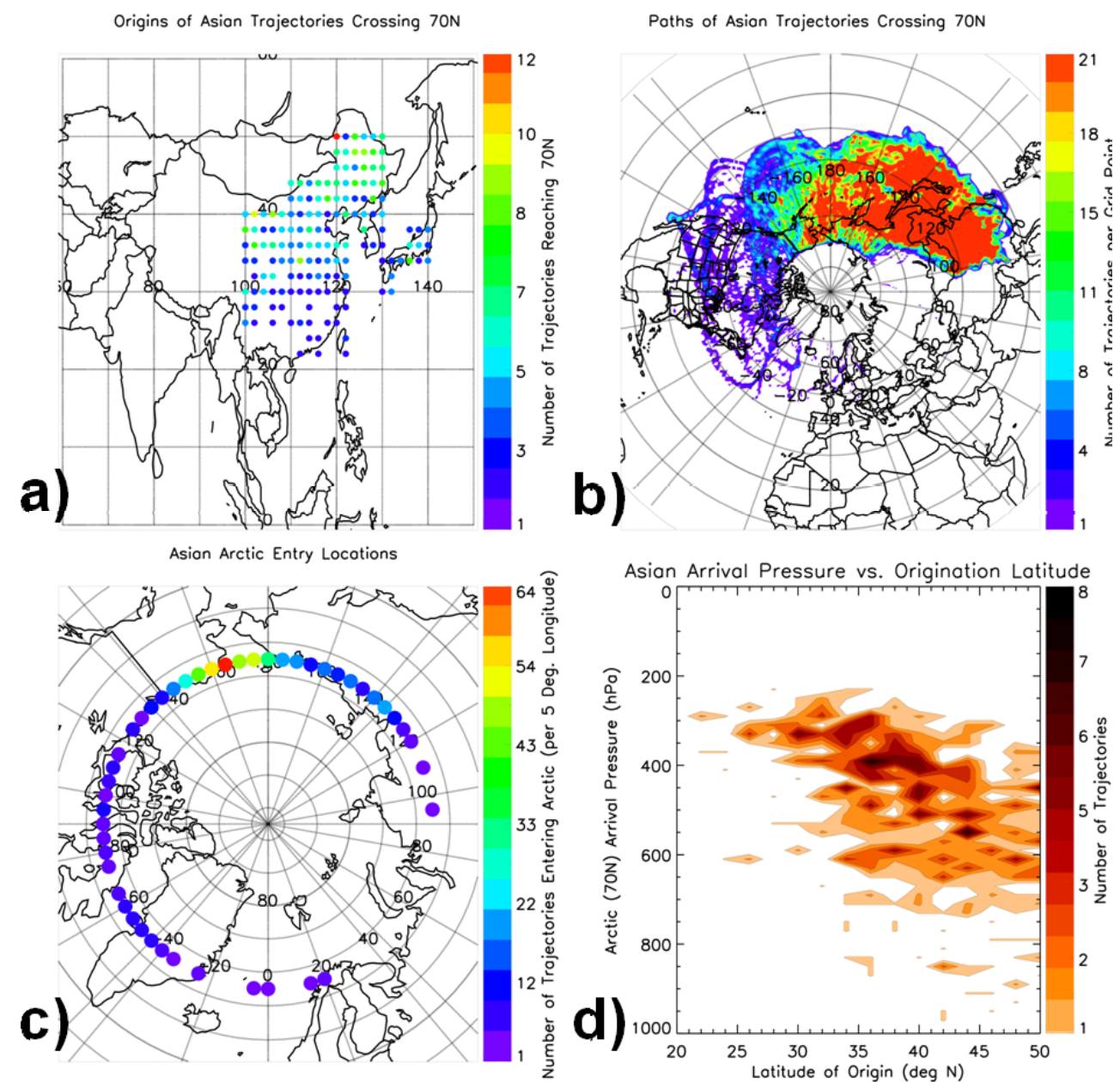

Fig. 4. Trajectory statistics for the eastern Asia domain. (a) Number and originating locations of trajectories reaching the Arctic $\left(70^{\circ} \mathrm{N}\right)$ within 15 days. (b) Pathways taken by all 15 day trajectories reaching the Arctic. (c) Number and location of trajectories entering the Arctic. (d) Pressure level at which Arctic bound trajectories arrive at $70^{\circ} \mathrm{N}$.

\section{Eastern asian case study}

We now present an example of Asian anthropogenic transport using chemical tracers sampled by the DC- 8 and backward trajectories from these sampling sites. We fingerprint the source region of the sampled anthropogenic emissions and describe its transport pathway and the weather patterns responsible for this transport. Asian emissions have been found to be more efficient in producing tropospheric ozone than European and North American sources (Stohl et al., 2002). Thus, understanding the pathways and receptor regions of Asian anthropogenic emissions is important in understanding atmospheric chemistry budgets of the Arctic.

Leg 5 of DC-8 flight 8 on 12 April 2008 is an example of transport from Asia to the Arctic. This leg extends between 17:30 and 18:03 UTC, and is shown in Fig. 3b as the southernmost red segment, just south of Nunyak Island, AK.

\subsection{Chemical fingerprinting}

Asian outflow consists of a complex mixture of industrial, biofuel, and biomass burning emissions (Russo et al., 2003; Streets et al., 2003). Distinguishing anthropogenic influences from biomass burning emissions during ARCTAS-A is complex since the influence of biomass burning, especially from Russia, was significant (e.g., Warneke et al., 2009; Jacob et al., 2010; Kondo et al., 2011; Matsui et al., 2011; Oltmans et al., 2010; Singh et al., 2010). However, based on airborne measurements made during NASA's Intercontinental Chemical Transport Experiment (INTEX-B), Barletta et al. (2009) noted that China has a distinct anthropogenic chemical fingerprint consisting of enhanced levels of $\mathrm{OCS}, \mathrm{CH}_{3} \mathrm{Cl}, 1,2-$ DCE, ethyl chloride, and H-1211. The following description indicates that the ARCTAS flight 8, leg 5 chemical signature is consistent with that fingerprint. 
Carbonyl sulfide has several sources, including oceans, biomass burning, aluminum production, and coal combustion (Watts, 2000; Kettle et al., 2002; Blake et al., 2004). Sources of $\mathrm{CH}_{3} \mathrm{Cl}$ include biomass burning and biofuel use, while 1,2-dichloroethane primarily is anthropogenic and is used as a chemical intermediate in synthesizing other compounds (Barletta et al., 2009). Halon-1211, a purely anthropogenic tracer, is used in firefighting (Butler et al., 1998; Fraser et al., 1999). Halon-1211 also contributes to stratospheric ozone depletion, although its global abundance has begun to decline in recent years (http://cdiac.ornl.gov/trends/ otheratg/blake/data.html). Although $\mathrm{CH}_{3} \mathrm{Cl}$ and OCS can have both anthropogenic and biomass burning sources, their origins can reasonably be classified as anthropogenic when well correlated with $\mathrm{H}-1211$ and 1,2-DCE. These species, as well as tetrachloroethene $\left(\mathrm{C}_{2} \mathrm{Cl}_{4}\right.$, an industrial solvent and purely anthropogenic tracer) and HCFC-22 (a refrigerant and purely anthropogenic tracer) (Aucott et al. 1999; Blake et al., 2003) are plotted in Fig. 5 with respect to sampling altitude along DC-8 flight 8 on 12 April 2008.

Sampling altitudes as well as mixing ratios identify three data points between $7500-8300 \mathrm{~m}$ that represent the plume sampled along leg 5. The figure contains six composite plots with leg 5 indicated by the red points. The blue points also denote data from leg 5, specifically the subset of leg 5 data that represents the plume that will be examined. All other legs along flight 8 are represented by the black points.

Figure 5a-d show the tracers described by Barletta et al. (2009) as being an anthropogenic fingerprint for China. It is clear that the data points representing the plume (blue) are enhanced over the background values for the flight. Furthermore, a relatively strong average correlation $\left(r^{2}=0.81\right)$ between these four tracers supports the conclusion that OCS and $\mathrm{CH}_{3} \mathrm{Cl}$ within the leg 5 plume are of anthropogenic origin. Further strengthening the hypothesis that anthropogenic emissions were sampled along leg 5 is the fact that two purely anthropogenic tracers $\left(\mathrm{C}_{2} \mathrm{Cl}_{4}\right.$ and HCFC-22, Fig. 5e, f) are enhanced over background values. In particular, $\mathrm{C}_{2} \mathrm{Cl}_{4}$ showed very good correlation with the four tracers of air of Chinese origin (H-1211, OCS, 1,2-DCE, CH3Cl), with $\mathrm{r}^{2}$ values between ranging from 0.79 to 0.99 .

Mean background mixing ratios for each of the species above were determined using data from ARCTAS-A flights 4-10 (as described in Sect. 2.4) and are presented in Table 2. These values are compared with mean mixing ratios in the plume along leg 5. All species listed in Table 2 exhibit greater mixing ratios in the leg 5 Asian plume than in background air measured during ARCTAS-A. The mean values of 1,2-DCE, $\mathrm{C}_{2} \mathrm{Cl}_{4}, \mathrm{CH}_{3} \mathrm{Cl}$, OCS, HCFC-22, and $\mathrm{H}-$ 1211 in the Asian plume are enhanced by 420, 61, 30, 26, 8 and $7 \%$, respectively, over their mean background values (Table 2). One should note that these relative enhancements generally decrease with increasing atmospheric lifetime of each compound. This is consistent with longer-lived species being more abundant (higher background values) in the atmosphere, therefore producing relatively smaller enhancements.

To summarize, enhancements in three purely anthropogenic tracers $\left(\mathrm{C}_{2} \mathrm{Cl}_{4}, \mathrm{H}-1211\right.$, and $\left.\mathrm{HCFC}-22\right)$ signal an anthropogenic influence along leg 5 of flight 8 on 12 April 2008. Furthermore, four species known to be specific to Chinese anthropogenic emissions (1,2-DCE, OCS, $\mathrm{H}-1211$, and $\mathrm{CH}_{3} \mathrm{Cl}$ ) (Barletta et al., 2009) are well correlated along leg 5. The two species that can have either biomass or anthropogenic emissions (OCS and $\mathrm{CH}_{3} \mathrm{Cl}$ ) are concluded to be of anthropogenic origins since they are well correlated with the remaining two anthropogenic tracers $(\mathrm{H}-$ 1211 and 1,2-DCE). Furthermore, the anthropogenic signature along leg 5 is enhanced compared to all other flights during ARCTAS-A. Thus, based on chemistry alone, Chinese anthropogenic emissions were sampled along leg 5. Note that air from other regions of Asia such as Japan or Korea have their own chemically distinct signatures (Blake et al., 2003), and we are able to specifically attribute the leg 5 samples to source influences from China. The Chinese source is examined from a meteorological perspective in the next section.

\subsection{Transport and meteorology}

Fifteen day backward trajectories were calculated at 1 min intervals along flight leg 5 within the 500-300 hPa layer, for a total of 34 releases. We monitored whether each trajectory passed into the model-derived boundary layer during its transit, and all 34 trajectories were found to have done so (Fig. 6a). Boundary layer encounters are important since they indicate that surface based emissions are accessed for transport. Figure $6 \mathrm{~b}$ shows only those segments of the trajectories in Fig. 6a that are in the boundary layer. In combination with the trajectories in Fig. 6a and b, we examined meteorological conditions at numerous constant pressure levels (e.g., 850,500 , and $300 \mathrm{hPa}$ ) to determine the factors contributing to the transport of emissions.

Going backward in time from the aircraft's location, the trajectories split into two branches as they pass over the Sea of Okhotsk (Fig. 6a). Branch 1 is the most dispersive, with many trajectories located over Asia 15 days prior to sampling. The paths become more consolidated as the trajectories pass over the Koreas and then make a loop near $35^{\circ} \mathrm{N}$, $175^{\circ} \mathrm{E}$ before heading toward southern Alaska and the DC-8. Average locations of the trajectories when the boundary layer is encountered are shown in Figs. $6 \mathrm{~b}$ and $7 \mathrm{a}$, while Fig. $7 \mathrm{~b}$ shows where the strong ascent occurs. The number within each red circle of Fig. 7 is the time (in days) prior to the flight encounter. Ten days prior to DC-8 sampling (Fig. 7a), the trajectories are located in the boundary layer over eastern Asia, just north of the Koreas, where anthropogenic emissions are enhanced (Fig. 2b). The trajectories then move offshore over the western Pacific to a position south of the Kamchatka Peninsula and follow a looping track for the next 

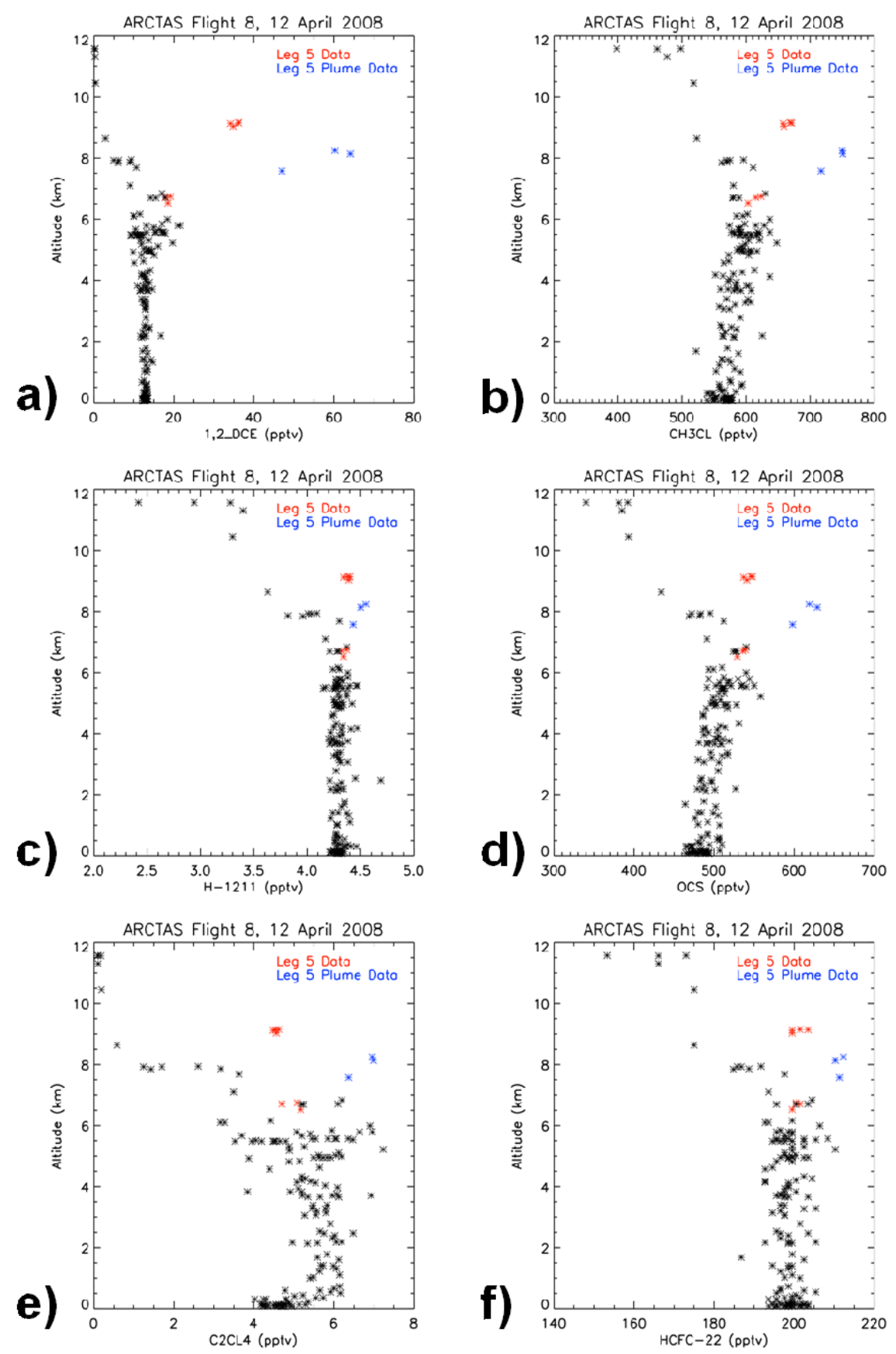

Fig. 5. Vertical distributions of data from flight 8 on 12 April 2008 for (a) 1,2-DCE, (b) $\mathrm{CH}_{3} \mathrm{Cl}$, (c) $\mathrm{H}-1211$, (d) $\mathrm{OCS}$, (e) $\mathrm{C}_{2} \mathrm{Cl} l_{4}$, and (f) HCFC-22. Red points are data from leg 5. Blue points also are from leg 5 but represent the sampled plume. Black points represent the remaining legs of flight 8 .

five days (Fig. 6a) due to a series of troughs and ridges over the northwest Pacific. A low pressure system develops off the eastern coast of Japan, strengthens, and moves northward during the final three days of transit (Fig. 7b). The trajectories are located in the warm sector of this middle latitude cyclone where they experience rapid ascent and arrive at the aircraft under the influence of upper level westerly flow.
Branch 2 of the trajectories comprising leg 5 (Fig. 6a) exhibits a more direct route to the DC- 8 . Figure 8 shows their average locations both when the boundary layer is encountered (Fig. 8a) and when deep ascent occurs (Fig. 8b). Fifteen days prior to aircraft sampling, the trajectories are in the boundary layer over southern Asia near Bangladesh and Bhutan (Figs. 6b, 8a). Similar to branch 1, this is an area of 


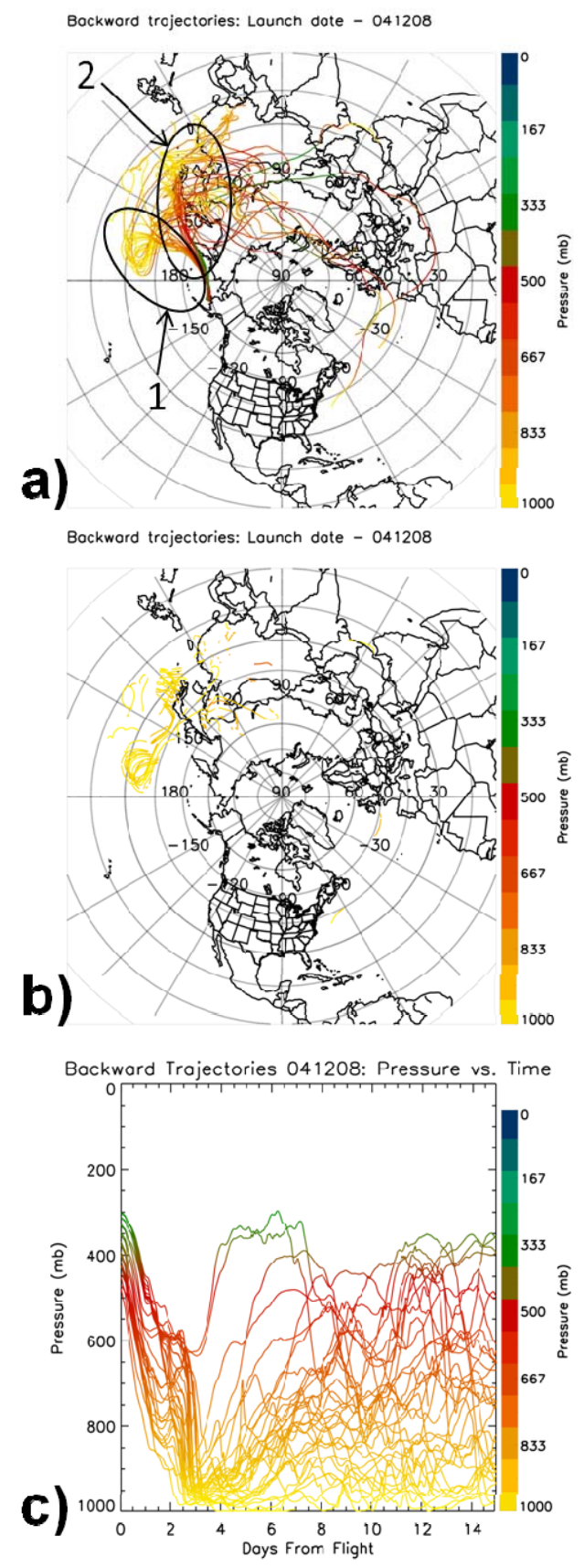

Fig. 6. Fifteen day backward trajectories for (a) all trajectories associated with leg 5 that encountered the boundary layer sometime during their 15 day transit, (b) only those segments of trajectories in (a) when the boundary layer is experienced, and (c) pressure vs. time plot for trajectories from leg 5 that encountered the boundary layer. The two numbered elliptical areas in (a) represent groups of trajectories that are discussed in the text.

major anthropogenic emissions (Fig. 2b). The weather pattern is rather benign at this time, and the trajectories take a slow, almost negligible eastward track through the lower troposphere for the next several days (Fig. 8a). At 3 days prior to sampling (Fig. 8b) they are east of Japan in the warm sec-
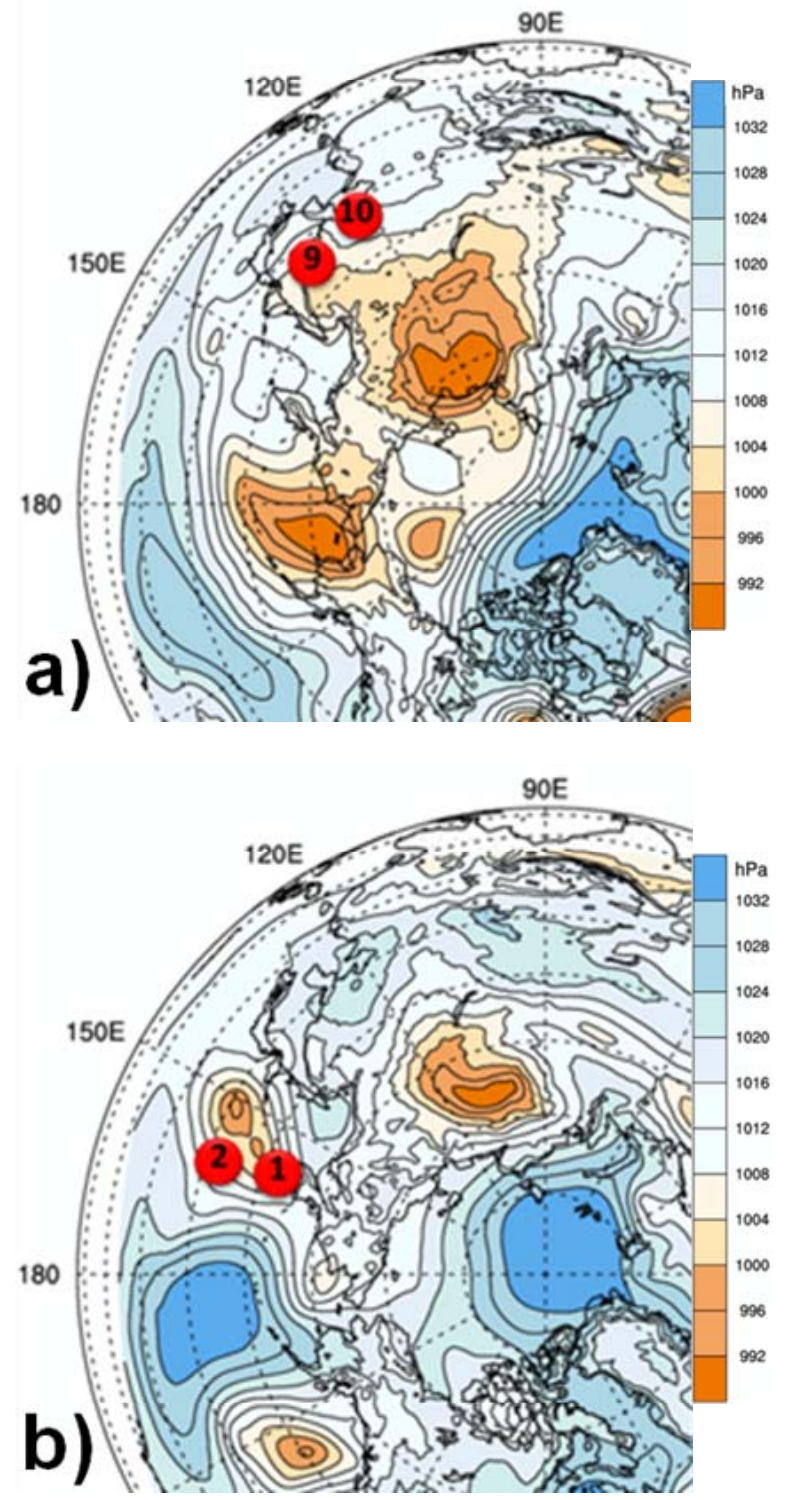

Fig. 7. Average location of trajectories comprising the easternmost branch in Fig. 6a (red circles) for (a) 9-10 days back from the flight, and (b) 1-2 days back.

tor of a middle latitude cyclone where they undergo ascent. For the remainder of the time until reaching the aircraft, they are transported northeastward in the upper troposphere.

Figure $6 \mathrm{c}$ presents the trajectories from Fig. $6 \mathrm{a}$ in a pressure versus time reference frame. Both branches of trajectories experience deep ascent during the 4 days prior to flight 8. The distribution on earlier days is poorly defined due to the different paths taken by the individual trajectories. Synoptic analyses indicate that the strong ascent occurs when the trajectories are within a cyclone's warm sector (Figs. 7b, 8b), suggesting that the ascent may be due to a warm conveyor belt (WCB). 

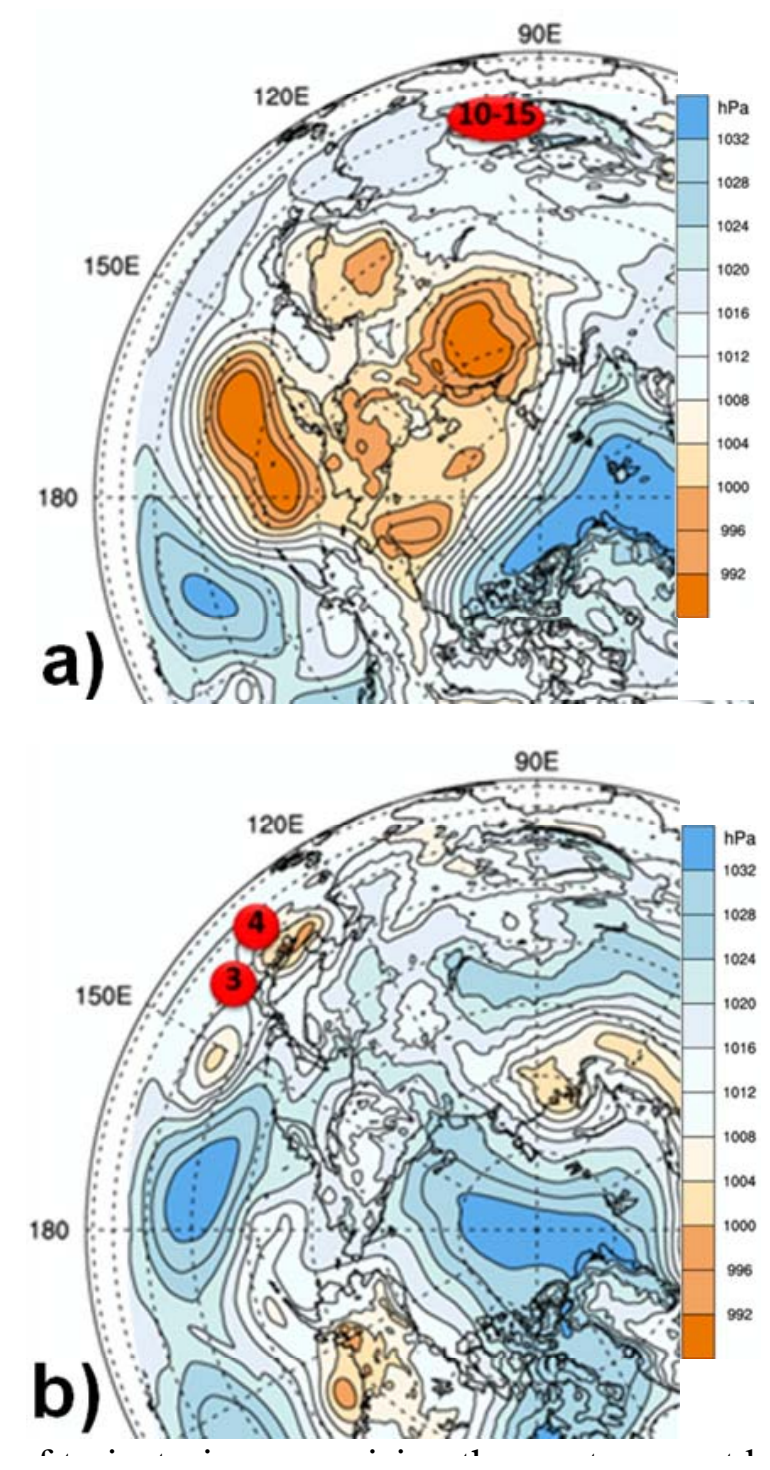

Fig. 8. Average location of trajectories comprising the westernmost branch in Fig. 6a (red circles) for (a) 10-15 days back from the flight, and (b) 3-4 days back.

We examined each of the leg 5 boundary layer trajectories (Fig. 6a) to determine if they satisfied the "reasonably strong" WCB criteria in Eckhardt et al. (2004) (Sect. 2.3). The 2 day periods were calculated back from each hourly position along the trajectory path. Results show that $100 \%$ of the trajectories met the required northward and eastward displacement criteria during a 2 day period. We then determined whether the trajectories' ascent exceeded $60 \%$ of the tropopause height as defined by our WRF simulations. Although the tropopause height varies spatially and temporally, its average height in our $30-60^{\circ} \mathrm{N}$ window (where the ascent occurred) was $10366 \mathrm{~m}$, agreeing closely with the values in Eckhardt et al. (2004). Sixty percent of the average tropopause height is $6219 \mathrm{~m}$. Results show that $71 \%$ of the trajectories in Fig. 6a ascend at least this amount during a $48 \mathrm{~h}$ period. Finally, we calculated the $48 \mathrm{~h}$ change in potential temperature along the leg 5 trajectories in Fig. 6a. Fiftysix percent of them satisfy the $15-22 \mathrm{~K}$ increase criterion, with $95 \%$ of these cases coinciding with ascent greater than $60 \%$ of the tropopause height. If we assume that either the horizontal and vertical criteria, or the horizontal and potential temperature criteria must be met for WCB processes to be verified, our percentage increases from 71 to $74 \%$. Although not all of the leg 5 trajectories satisfy each of the Eckhardt et al. (2004) WCB criteria, many do, and all of the trajectories fulfill the horizontal requirements. These results strongly suggest that most of the trajectories in Fig. 6a did experience "reasonably strong" WCB processes as defined by Eckhardt et al. (2004).

In summary, these sections have detailed model-derived transport from Asia, chemical fingerprinting based on in situ aircraft measurements, as well as trajectory and meteorological analyses. The results have shown that chemical tracers specific to Asian and Chinese anthropogenic emissions were sampled during leg 5 of the flight. Trajectory analyses revealed that this air had intersected areas of enhanced anthropogenic emissions across eastern Asia within the boundary layer (Fig. 2b). The emissions then were transported eastward from the Asian continent where they most likely underwent WCB related ascent prior to reaching the DC-8 at flight level on 12 April 2008.

\section{North American transport during ARCTAS-A}

We next examine the transport of North American anthropogenic emissions to the Arctic. Forward trajectories were initiated at 178 grid points over North American anthropogenic sources (Fig. 2c, d) each day during ARCTAS-A, producing a total of 5518 releases during the 31 day period. The origination points of trajectories which entered the Arctic are distributed primarily over the northern half of the region (Fig. 9a). Origins at latitudes greater than $40^{\circ} \mathrm{N}$ produce $47 \%$ of the Arctic bound trajectories, while $50 \%$ of the trajectories originate between $30-40^{\circ} \mathrm{N}$. Only a small percentage $(3 \%)$ of trajectories originating at latitudes less than $30^{\circ} \mathrm{N}$ reach the Arctic within 15 days. A close examination of the trajectories crossing $70^{\circ} \mathrm{N}$ (Fig. 9b), reveals two major pathways (red areas). The most distinct pathway transports air north from its origination. This path continues across northeastern Canada and enters the Arctic over Baffin Bay. A less defined pathway takes trajectories eastward across the North Atlantic Ocean and over Europe. From there they disperse and enter the Arctic in a disorganized pattern.

Entry regions to the Arctic $\left(70^{\circ} \mathrm{N}\right)$ are shown in Fig. 9c. The most prominent entrance region is between Nunavut, Canada and Greenland, a common pathway seen in Fig. $9 b$. Of the trajectories that enter the Arctic from North America 

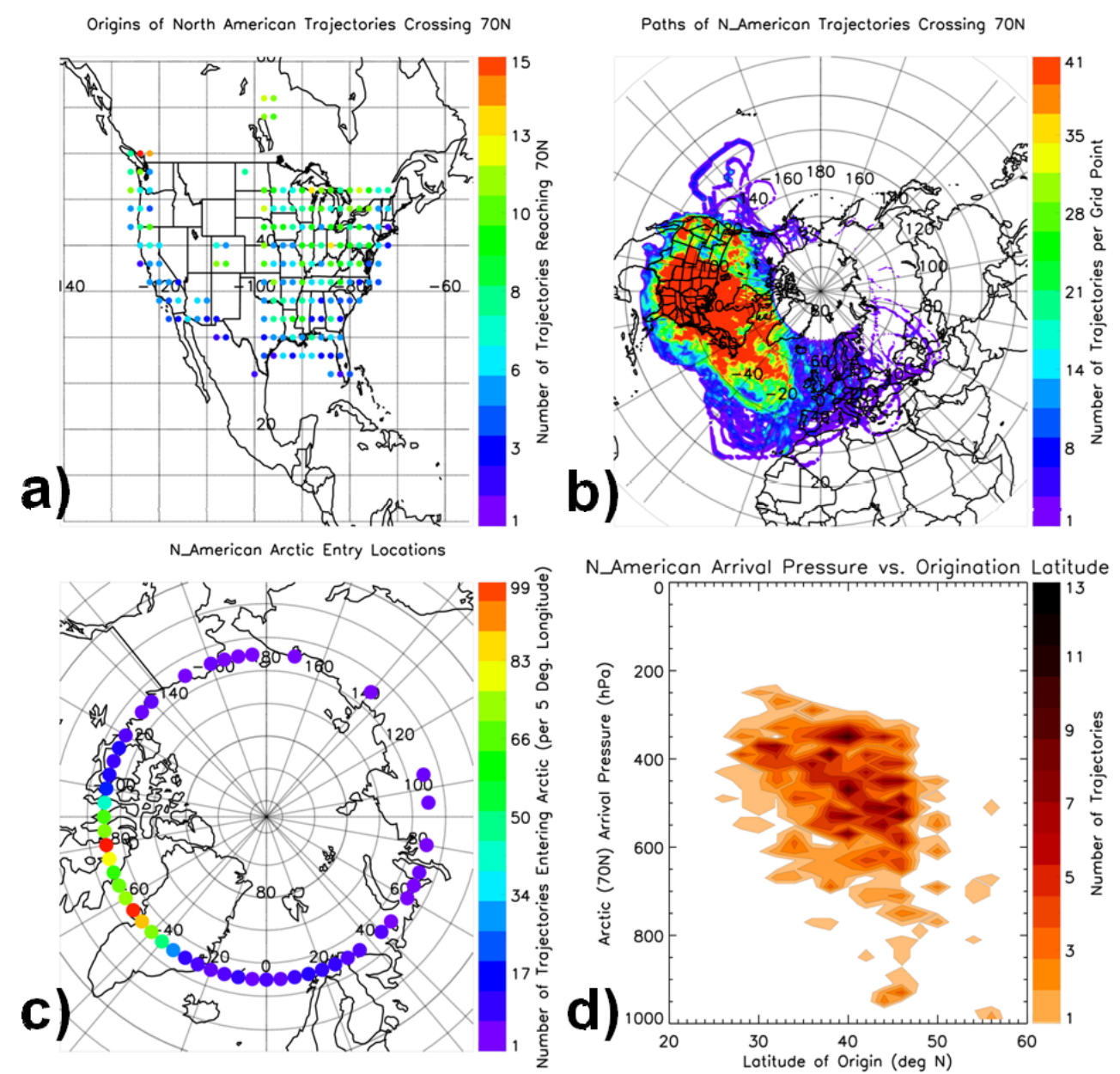

Fig. 9. As in Fig. 4, but for North American trajectories.

within 15 days, $85 \%$ arrive between $40-100^{\circ} \mathrm{W}$. A much smaller percentage (14\%) enters the Arctic across northern Europe between $40^{\circ} \mathrm{W}$ and $40^{\circ} \mathrm{E}$. This region also is depicted in Fig. 9b. The remaining $1 \%$ enters the Arctic sporadically along the $70^{\circ} \mathrm{N}$ latitude ring.

The distribution of altitudes at which trajectories arrive in the Arctic (Fig. 9d) is similar to that for the Asian domain (Fig. 4d). Most trajectories initiated over North America enter the Arctic in the middle (42\%) and upper troposphere (53\%); only $5 \%$ arrive in the lower troposphere. These pathways are consistent with previous studies (Klonecki et al., 2003; Stohl, 2006; Law and Stohl, 2007).

\section{North American case study}

DC-8 flight 5 on 5 April 2008 contains an example of transport from North America to the Arctic. Leg 8, between 16:27-17:13 UTC, is shown in Fig. 3a as the red segment between Baffin Island, Canada and Disko Bay, Greenland.

\subsection{Chemical fingerprinting}

Volatile organic compounds, including nonmethane hydrocarbons (NMHCs), generally reach maximum concentrations over the United States during the winter months when $\mathrm{OH}$ production and photochemistry are at a seasonal minimum (Russo et al., 2010). Concentrations decline during spring, reaching a minimum during the summer months when photochemistry is most active. Some of these VOCs undergo chemical reactions in the presence of nitrogen oxides to produce ozone, a component of photochemical smog (Carter, 1994; Russo et al., 2010). It is important to note that NMHCs from urban locations in the United States are primarily anthropogenic (Lee et al., 2006).

Figure 10 contains plots of $\mathrm{C}_{2} \mathrm{H}_{6}, \mathrm{C}_{3} \mathrm{H}_{8}, \mathrm{C}_{6} \mathrm{H}_{6}, \mathrm{HCFC}-22$, and $\mathrm{C}_{2} \mathrm{Cl}_{4}$ with respect to altitude during the 5 April 2008 flight. Similar to the previous figure of this type (Fig. 5), data for flight legs other than leg 8 are in black. However, since all data points in the North American leg represent the sampled plume, the entire suite of data for leg 8 is colored 

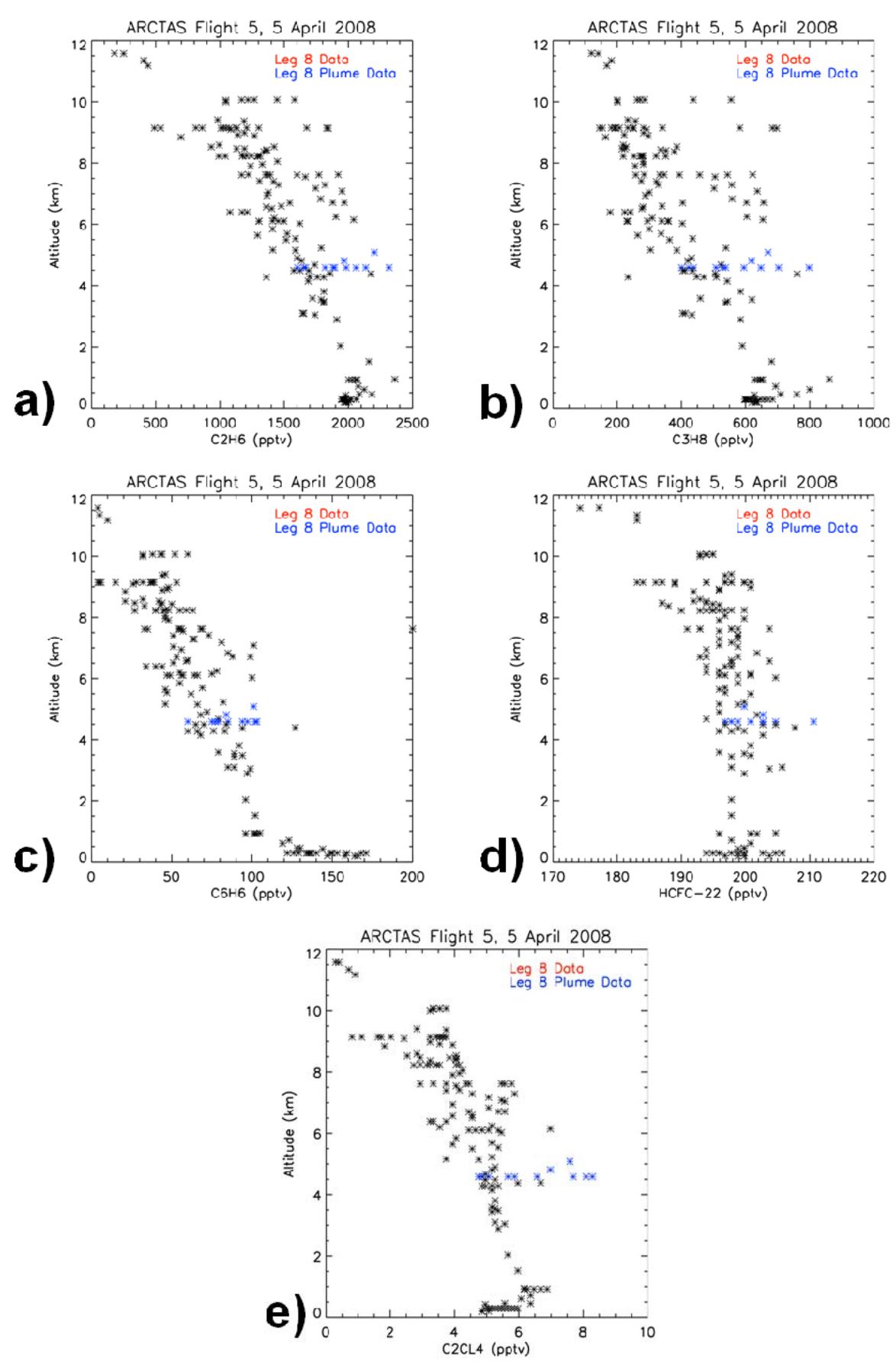

Fig. 10. Vertical distributions of data from flight 5 on 5 April 2008 for (a) $\mathrm{C}_{2} \mathrm{H}_{6}$, (b) $\mathrm{C}_{3} \mathrm{H}_{8},(\mathbf{c}) \mathrm{C}_{6} \mathrm{H}_{6}$, (d) $\mathrm{HCFC}_{-22}$, and (e) $\mathrm{C}_{2} \mathrm{Cl}_{4}$. Blue points are from leg 8 , representing the sampled plume. In this case the plume is represented by all of the data points along leg 8 . Black points represent the remaining legs of flight 5 .

blue. These data were determined to be from the same plume since they all experienced enhancements over their respective background values, and they were sampled in the same altitude range (4500-5000 m).

The incomplete combustion (IC) tracer $\mathrm{C}_{6} \mathrm{H}_{6}$ (Fig. 10c), as well as two purely anthropogenic tracers (HCFC-22 and
$\mathrm{C}_{2} \mathrm{Cl}_{4}$, Fig. 10d, e), whose origins were discussed in the previous case study, exhibit enhancements along leg 8 . Since our IC tracer can have either biomass burning or anthropogenic origins, we correlated it with the known anthropogenic species $\mathrm{C}_{2} \mathrm{Cl}_{4}$ to determine its source. The two are well correlated $\left(r^{2}=0.72\right)$; thus, we can assume $\mathrm{C}_{6} \mathrm{H}_{6}$ has 
anthropogenic sources. In addition, $\mathrm{C}_{2} \mathrm{H}_{6}$ and $\mathrm{C}_{3} \mathrm{H}_{8}$ (also enhanced along leg 8, Fig. 10a, b, respectively)-two natural gas tracers that also are emitted from biomass burning-show good correlation with the anthropogenic tracer $\mathrm{C}_{2} \mathrm{Cl}_{4}\left(r^{2}=\right.$ 0.86 and $r^{2}=0.90$, respectively). Therefore, the data suggest that an urban/industrial influence is much more likely than a biomass burning influence.

Similar to Table 2, Table 3 presents mean background mixing ratios of the species discussed above during ARCTAS-A for comparison with mean mixing ratios from the plume sampled along leg 8 . The species listed in Table 3 exhibit higher mixing ratios in the leg 8 North American plume than in the background air. Mean values of $\mathrm{C}_{3} \mathrm{H}_{8}, \mathrm{C}_{6} \mathrm{H}_{6}, \mathrm{C}_{2} \mathrm{Cl}_{4}, \mathrm{C}_{2} \mathrm{H}_{6}$ and HCFC-22 in the North American plume are enhanced by $83,76,51,37$ and $3 \%$, respectively, over their mean background values (Table 3 ).

In summary, two purely anthropogenic species $\left(\mathrm{C}_{2} \mathrm{Cl}_{4}\right.$ and HCFC-22) were enhanced over the background in the North American plume. Tetrachloroethene correlated well with benzene, a non-specific tracer of incomplete combustion, as well as two natural gas tracers $\left(\mathrm{C}_{3} \mathrm{H}_{8}\right.$ and $\left.\mathrm{C}_{2} \mathrm{H}_{6}\right)$, strongly suggesting anthropogenic rather than biomass burning sources. These data suggest that the DC- 8 sampled anthropogenic emissions along leg 8 of the ARCTAS flight on 5 April 2008. The North American source is examined further in the next section.

\subsection{Transport and meteorology}

Backward trajectories were released from the aircraft location each minute along flight leg 8 within the $600-500 \mathrm{hPa}$ layer, for a total of 47 releases. As before, each trajectory was examined to determine whether it entered the boundary layer along its path; 39 trajectories were found to have done so (Fig. 11a). Boundary layer occurrences of the trajectories in Fig. 11a are shown in Fig. 11b. Most of the trajectories follow a complex looping path as described below. Although 4 of the 39 boundary layer trajectories travel westward across the United States and encounter the clean boundary layer of the northern Pacific Ocean, the majority of boundary layer occurrences are located along the east coast of North America where anthropogenic emissions are enhanced (Fig. 2d).

Similar to the previous case, the trajectories in Fig. 11a and b, combined with WRF constant pressure analyses (Fig. 12), are examined to determine the factors contributing to the transport of emissions. Fifteen days prior to the DC-8 sampling anthropogenic emissions, the average location of the East Coast trajectories is over Baffin Bay (Fig. 11a), close to their later sampling location. They then move in a generally looping pattern over northeastern Canada and the northeastern US for $\sim 10$ days (Fig. 11a) due to a series of cyclones and anticyclones in the area. The trajectories are located along the northeastern US coastline five days prior to the flight (Fig. 12a). It is between 4 and 5 days back from the flight that the most trajectories encounter the boundary layer along the North American coastline where anthropogenic emissions are at their greatest (Figs. 11b, 12a, 2d). A surface low over the Great Lakes places the trajectories in a region of southwesterly flow, transporting them northeastward toward Prince Edward Island. The low strengthens and transports the trajectories into its warm sector 3 days prior to the flight (Fig. 12b). It is here that the trajectories undergo ascent that lofts them into the upper troposphere. Finally, they round the base of a middle tropospheric trough before travelling northwestward to the DC-8.

Figure $11 \mathrm{c}$ shows deep ascent beginning $\sim 4$ days prior to sampling. This corresponds to the time that the trajectories are located within the cyclone's warm sector (Fig. 12b). Thus, a WCB was suspected to be the cause of the ascent. The methods used previously to define "reasonably strong" WCB transport (Eckhardt et al., 2004) again were employed. All of the trajectories examined along leg 8 satisfy the horizontal WCB requirements. The average tropopause height between $40^{\circ} \mathrm{N}$ and $60^{\circ} \mathrm{N}$ was $9644 \mathrm{~m}$, with $60 \%$ of this value being $5787 \mathrm{~m}$. Although no trajectories satisfy this ascent criterion, $44 \%$ of the trajectories meet the $15-22 \mathrm{~K}$ increase in potential temperature criterion, It is important to note the strong seasonal variability in WCB frequency and associated vertical mass flux, with maxima during winter and minima in summer (Stohl, 2001; Eckhardt et al., 2004). Since ARCTAS-A occurred during a transitional season, the $60 \%$ ascent requirement may be too strict for spring, causing valid WCBs to be neglected. If we reduce the vertical criterion to $40 \%$ of the tropopause height $(3858 \mathrm{~m}), 72 \%$ of the trajectories satisfy the requirement. Furthermore, $94 \%$ of those satisfying the potential temperature criterion also satisfy the revised ascent criterion. Considering horizontal motion, the change in potential temperature, and the reduced ascent criterion, $74 \%$ of the leg 8 trajectories satisfy the revised WCB requirement. This information and the synoptic patterns described above suggest that the leg 8 trajectories experienced ascent due to a WCB.

To summarize, chemical fingerprinting and meteorological analyses indicate that the DC- 8 sampled North American anthropogenic emissions during leg 8 of the 5 April 2008 flight. Vertical distribution plots and comparisons with background mixing ratios revealed enhancements during this leg, including tracers having purely anthropogenic sources. Trajectory analysis showed that boundary layer air was encountered along the northeastern US coast where anthropogenic emissions are a maximum (Fig. 2d). Finally, the trajectories underwent suspected WCB related ascent to the middle troposphere where the emissions were sampled by the DC- 8 .

\section{European transport during ARCTAS-A}

Fifteen day forward trajectories were initialized from the 224 grid points with European anthropogenic emissions (Fig. 2e, f) on each of the 31 ARCTAS-A days, producing a total 

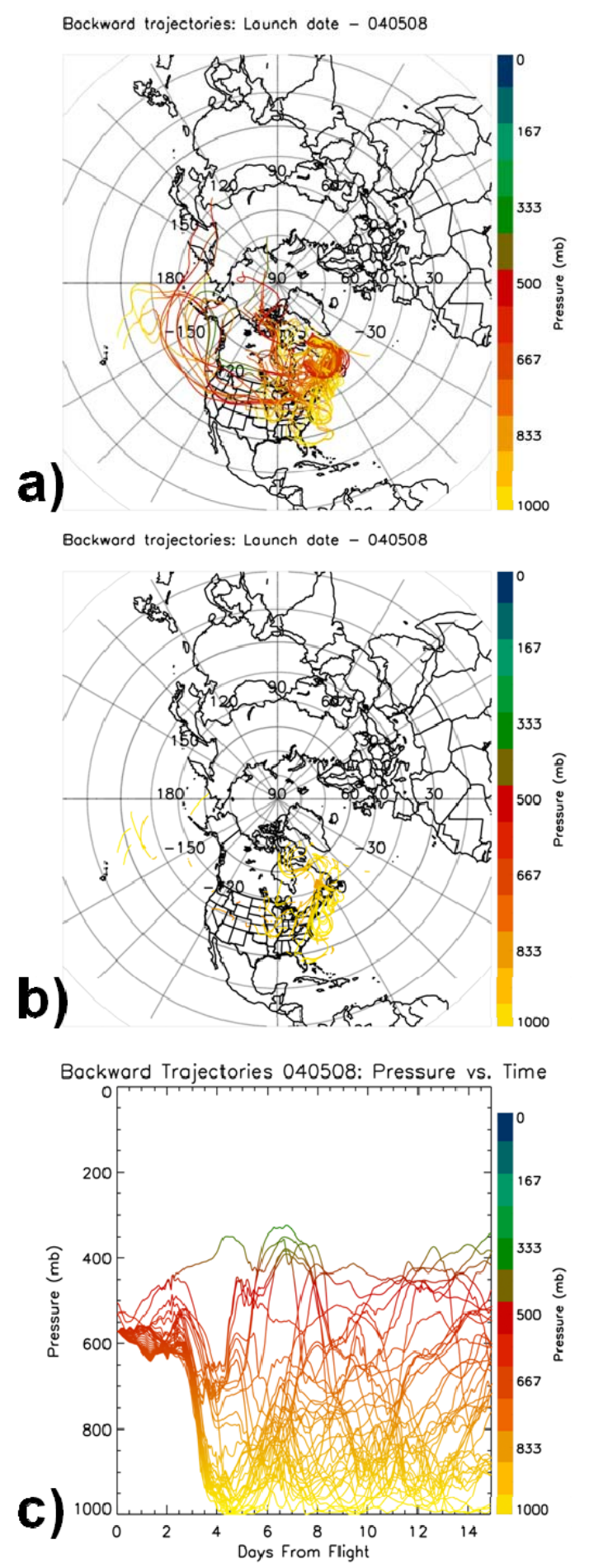

Fig. 11. As in Fig. 6, but for leg 8 on 5 April 2008.

of 6944 releases. Only a few initiation points in the far southeastern domain do not produce Arctic bound trajectories within the 15 day period (Fig. 13a). Of the total trajectories released, $1936(28 \%)$ reach the Arctic $\left(70^{\circ} \mathrm{N}\right)$ within 15 days. Of the trajectories reaching the Arctic, $32 \%$ orig-
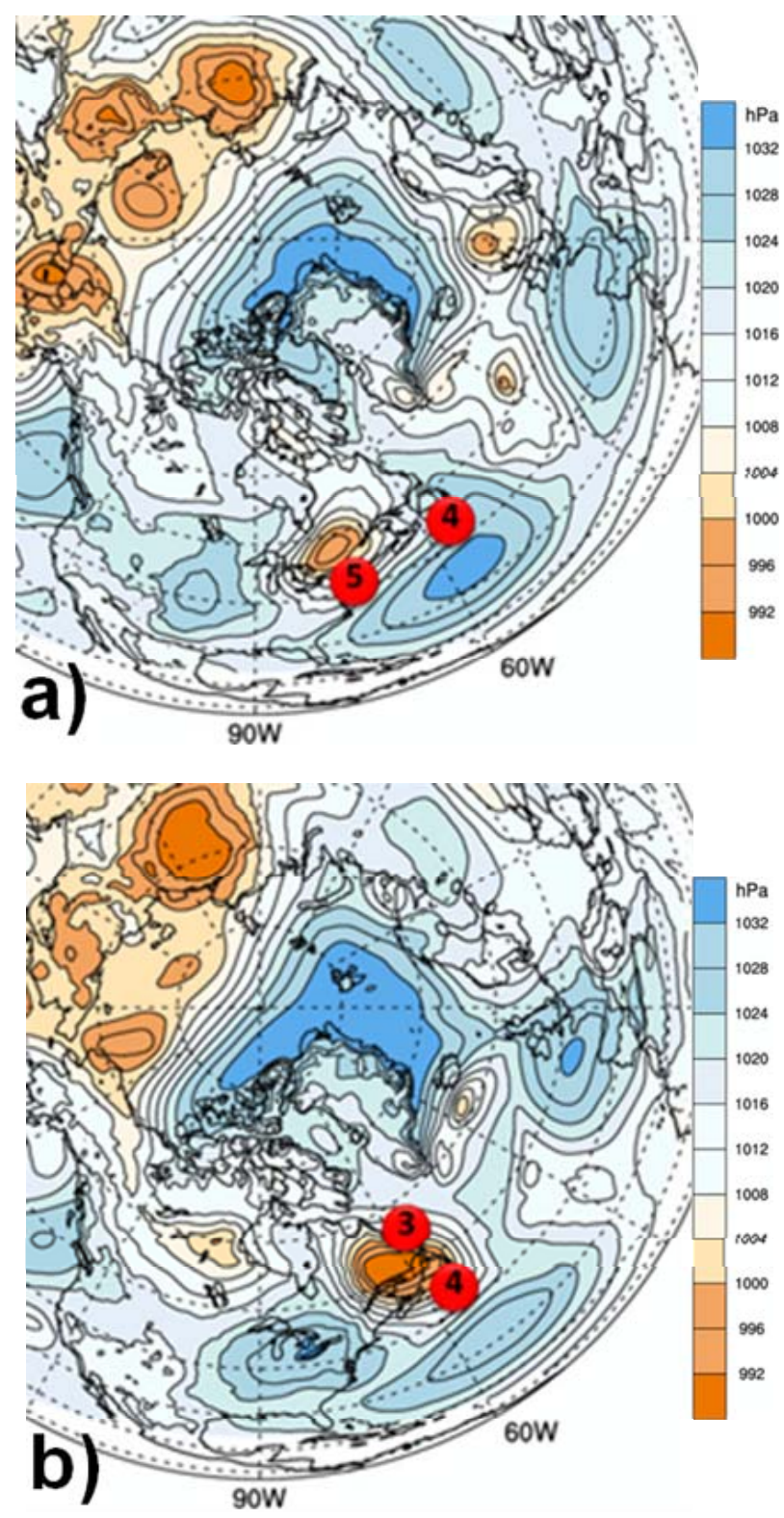

Fig. 12. Average positions of the group of trajectories released from leg 8 of DC-8 flight 5 on 5 April 2008. Red circles denote locations at (a) 4-5 days back and (b) 3-4 days back.

inate at latitudes greater than $50^{\circ} \mathrm{N} ; 54 \%$ from between $40^{\circ} \mathrm{N}$ and $50^{\circ} \mathrm{N}$, and $14 \%$ at latitudes less than $40^{\circ} \mathrm{N}$. Most trajectories reaching the Arctic follow two general pathways (Fig. 13b). The first transports emissions northward across northern Europe before crossing $70^{\circ} \mathrm{N}$ (the red area). This path is most common for trajectories that remain in the lower troposphere. The second common pathway (red, then blue colors) begins with the trajectories moving eastward from the domain. They cross the Caspian Sea and continue eastward over Kazakhstan and then turn north to the Arctic. Although this is the most common track for trajectories that begin at the 

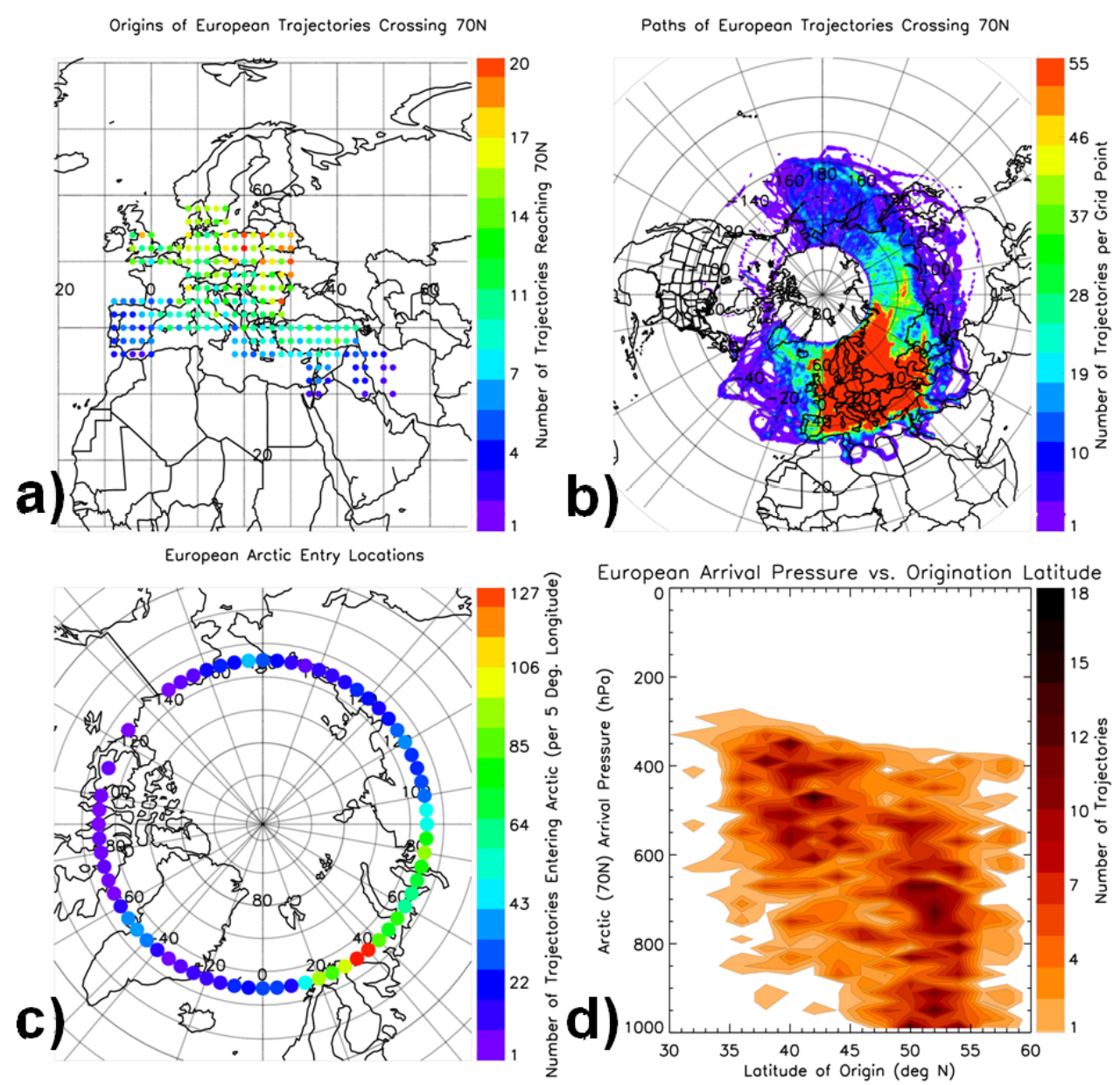

Fig. 13. As in Fig. 4, but for trajectories released from areas of European anthropogenic emissions.

surface and then ascend to the middle and upper troposphere, some do follow the first pathway.

Locations over northern Europe and northeastern Russia are the dominant entry region to the Arctic for trajectories originating from the European domain (Fig. 13c). This $70^{\circ}$ longitude region between $20-90^{\circ} \mathrm{E}$ accounts for $62 \%$ of the trajectories entering the Arctic. Secondary Arctic entry regions for trajectories originating from the European domain are similar to the primary Arctic entry regions from the other two domains (Figs. 4c and 9c, respectively). The longitude sector between $180^{\circ} \mathrm{W}$ and $140^{\circ} \mathrm{W}$ was a frequent entry region for Asian emissions $(61.5 \%)$ and accounts for $6 \%$ of the trajectories entering the Arctic from Europe. Likewise, the region between $100^{\circ} \mathrm{W}$ and $40^{\circ} \mathrm{W}$ was a common entry region for North American trajectories ( $85 \%$ ), and it accounts for $7 \%$ of the trajectories released from the European domain. Thus, considering the primary and secondary entry regions from the European domain, the trajectories enter the Arctic over a wide range of longitudes.
The altitudes at which European trajectories enter the Arctic (Fig. 13d) differ from the previous two domains (Figs. 4d and 9d). European releases arrive in the lower, middle, and upper troposphere, whereas trajectories from the previous domains were primarily in the middle and upper troposphere. Although the middle troposphere accounts for $56 \%$ of the European trajectories reaching the Arctic, the lower levels account for $17 \%$. This percentage arriving in the lower troposphere is considerably greater than the previous two regions (3\% from Asia and 5\% from North America). The increase in low-level arrivals is partly due to the more northerly European initiation locations compared to the other two regions. The trajectories enter the Arctic at the low levels by the processes mentioned in the Introduction (Klonecki et al., 2003; Stohl, 2006; Law and Stohl, 2007). The remaining $27 \%$ of Arctic bound trajectories from Europe arrive in the upper levels. 


\section{European case study}

Data from DC-8 flight 8 on 12 April 2008 comprise our case study of European emissions. This is the same flight on which Asian emissions were sampled, emphasizing the finding that many ARCTAS-A flights sampled air with multiple origins. The case focuses on the period 18:26-18:55 UTC which is denoted as leg 8 (leg 5 was studied for the Asian case). Leg 8 is located across the Bering Strait and over St. Lawrence Island, AK (Fig. 3b).

\subsection{Chemical fingerprinting}

We are not aware of previous research that provides a chemical fingerprint that is specific to European anthropogenic emissions. Thus, chemical considerations alone will not definitively link the sampled plume to a European source. Rather, the firm linkage with Europe will be based on a synthesis of trajectory and meteorological analyses.

The species examined for this case study are $\mathrm{C}_{2} \mathrm{Cl}_{4}, \mathrm{C}_{2} \mathrm{H}_{2}$, $\mathrm{C}_{6} \mathrm{H}_{6}, \mathrm{C}_{2} \mathrm{H}_{6}, \mathrm{C}_{3} \mathrm{H}_{8}$ and methane $\left(\mathrm{CH}_{4}\right)$ (Fig. 14). Similar to the other cases, the blue points (in Fig. 14) represent the sampled plume along leg 8 . This plume consists of 3 data points at almost the same altitude between 3704-3708 m. Each of the tracers being examined has been used and discussed in previous sections with the exception of $\mathrm{CH}_{4}$. Methane is introduced because when $\mathrm{CH}_{4}, \mathrm{C}_{2} \mathrm{H}_{6}$ and $\mathrm{C}_{3} \mathrm{H}_{8}$ are well correlated, natural gas emission can be inferred (Sect. 2.3). However, since $\mathrm{CH}_{4}, \mathrm{C}_{3} \mathrm{H}_{8}$ and $\mathrm{C}_{2} \mathrm{H}_{6}$ emissions can be from both biomass and anthropogenic sources, further examination is needed. First, the correlation for each of the natural gas tracers with the others was computed. The best correlations are between $\mathrm{C}_{2} \mathrm{H}_{6}$ and $\mathrm{C}_{3} \mathrm{H}_{8}\left(r^{2}=0.95\right)$, followed by $\mathrm{CH}_{4}$ and $\mathrm{C}_{3} \mathrm{H}_{8}\left(r^{2}=0.76\right)$, and $\mathrm{CH}_{4}$ and $\mathrm{C}_{2} \mathrm{H}_{6}\left(r^{2}=0.56\right)$. In addition to the fair to strong mutual correlations, this trio of gases also exhibits excellent correlation with the urban/industrial tracer $\mathrm{C}_{2} \mathrm{Cl}_{4}\left(r^{2}=0.91,0.83\right.$ and 0.96 for $\mathrm{CH}_{4}, \mathrm{C}_{2} \mathrm{H}_{6}$ and $\mathrm{C}_{3} \mathrm{H}_{8}$, respectively). This strongly suggests that $\mathrm{CH}_{4}, \mathrm{C}_{2} \mathrm{H}_{6}$ and $\mathrm{C}_{3} \mathrm{H}_{8}$ were co-emitted from an urban/industrial source such as natural gas usage, and not from biomass burning. Because ethane is the second most abundant component of natural gas after $\mathrm{CH}_{4}$ (Xiao et al., 2008), the relatively weaker correlations of $\mathrm{CH}_{4}$ with $\mathrm{C}_{2} \mathrm{H}_{6}$ and $\mathrm{C}_{3} \mathrm{H}_{8}$ may suggest that an additional urban source of $\mathrm{CH}_{4}$ also was present or that the strong $\mathrm{C}_{2} \mathrm{H}_{6}$ and $\mathrm{C}_{3} \mathrm{H}_{8}$ correlations represent a different fossil fuel source such as liquefied petroleum gas (LPG). Regardless, the light alkane signal is found to be urban in origin. Indeed, the two IC tracers $\left(\mathrm{C}_{2} \mathrm{H}_{2}\right.$ and $\left.\mathrm{C}_{6} \mathrm{H}_{6}\right)$ also show excellent correlation with $\mathrm{C}_{2} \mathrm{Cl}_{4}\left(r^{2}=0.99\right.$ and 0.73 , respectively), again consistent with an urban/industrial combustion source and not biomass burning.

Following the previously described methodology, Table 4 presents mean background mixing ratios during ARCTAS-A for the tracers used in this case, as well as mean values for the sampled plume along leg 8 . Similar to the previous two cases (Tables 2-3), the species in Table 4 have higher mixing ratios in the leg 8 European plume than in the background air measured during ARCTAS-A. Mean values of $\mathrm{C}_{6} \mathrm{H}_{6}, \mathrm{C}_{2} \mathrm{H}_{2}$, $\mathrm{C}_{3} \mathrm{H}_{8}, \mathrm{C}_{2} \mathrm{Cl}_{4}, \mathrm{C}_{2} \mathrm{H}_{6}$ and $\mathrm{CH}_{4}$ in the European plume are enhanced by $129,97,72,44,36$ and $2 \%$, respectively, over their mean background values (Table 4).

In summary, enhancements in the purely anthropogenic tracer $\mathrm{C}_{2} \mathrm{Cl}_{4}$ indicate that our plume is of anthropogenic origin. Generally good correlations between $\mathrm{CH}_{4}, \mathrm{C}_{2} \mathrm{H}_{6}$, $\mathrm{C}_{3} \mathrm{H}_{8}, \mathrm{C}_{2} \mathrm{Cl}_{4}, \mathrm{C}_{6} \mathrm{H}_{6}$ and $\mathrm{C}_{2} \mathrm{H}_{2}$ also show that anthropogenic emissions including combustion sources and possibly natural gas sources were sampled along leg 8 of DC- 8 flight 8 on 12 April 2008. The source of these emissions will be examined in the next section.

\subsection{Transport and meteorology}

Of all the DC-8 flights during April, flight 8 provides the most favorable trajectories for sampling boundary layer air over Europe, while avoiding large areas of biomass burning. A backward trajectory was initialized each minute along leg 8 within the $850-500 \mathrm{hPa}$ layer. Of the 30 total trajectories, 13 travel in the boundary layer at some time during their 15 day transit (Fig. 15a). The remaining 17 follow pathways that are similar to the boundary layer trajectories, but always remain above the boundary layer.

Knowing where the trajectories were in the boundary layer is especially important in this case because of a large area of fires across western Russia. Figure 16 shows a close up view of the trajectories from Fig. 15a, as well as a composite of all fire locations between 26 March and 6 April 2008 (the period when the trajectories were over Europe and Russia). Fire locations are from the Naval Research Laboratory (NRL) Fire Locating and Modeling of Biomass Burning Emissions (FLAMBE) dataset (Reid et al., 2009). The fires primarily are located between $50-60^{\circ} \mathrm{N}$, with their westernmost boundary across eastern Belarus and northeastern Ukraine. Figure $15 \mathrm{~b}$ shows the boundary layer segments of the trajectories in Fig. 15a. Most trajectories encounter the boundary layer across Europe, where fires are virtually absent. However, a few briefly encounter the boundary layer over western Russia, near the large region of fires. It is important to note that these brief incursions are not evident in the chemical data just described. Consistent with this, a biomass burning signature is not evident based on the measured mixing ratios of the biomass burning tracers $\mathrm{HCN}$ and $\mathrm{CH} 3 \mathrm{CN}$ (not shown). Thus, the brief fire area boundary layer encounters may be an artifact of trajectory uncertainty.

Most European trajectories follow one simple pathway (Fig. 15a). Fifteen days prior to aircraft sampling (Fig. 15a), the average location of the leg 8 trajectories is near $30^{\circ} \mathrm{W}$ over the northern Atlantic Ocean in a region of westerly flow. They continue in this westerly flow for several days and then pass over western Europe where they encounter the boundary layer (Fig. 17a) in an area of enhanced anthropogenic 

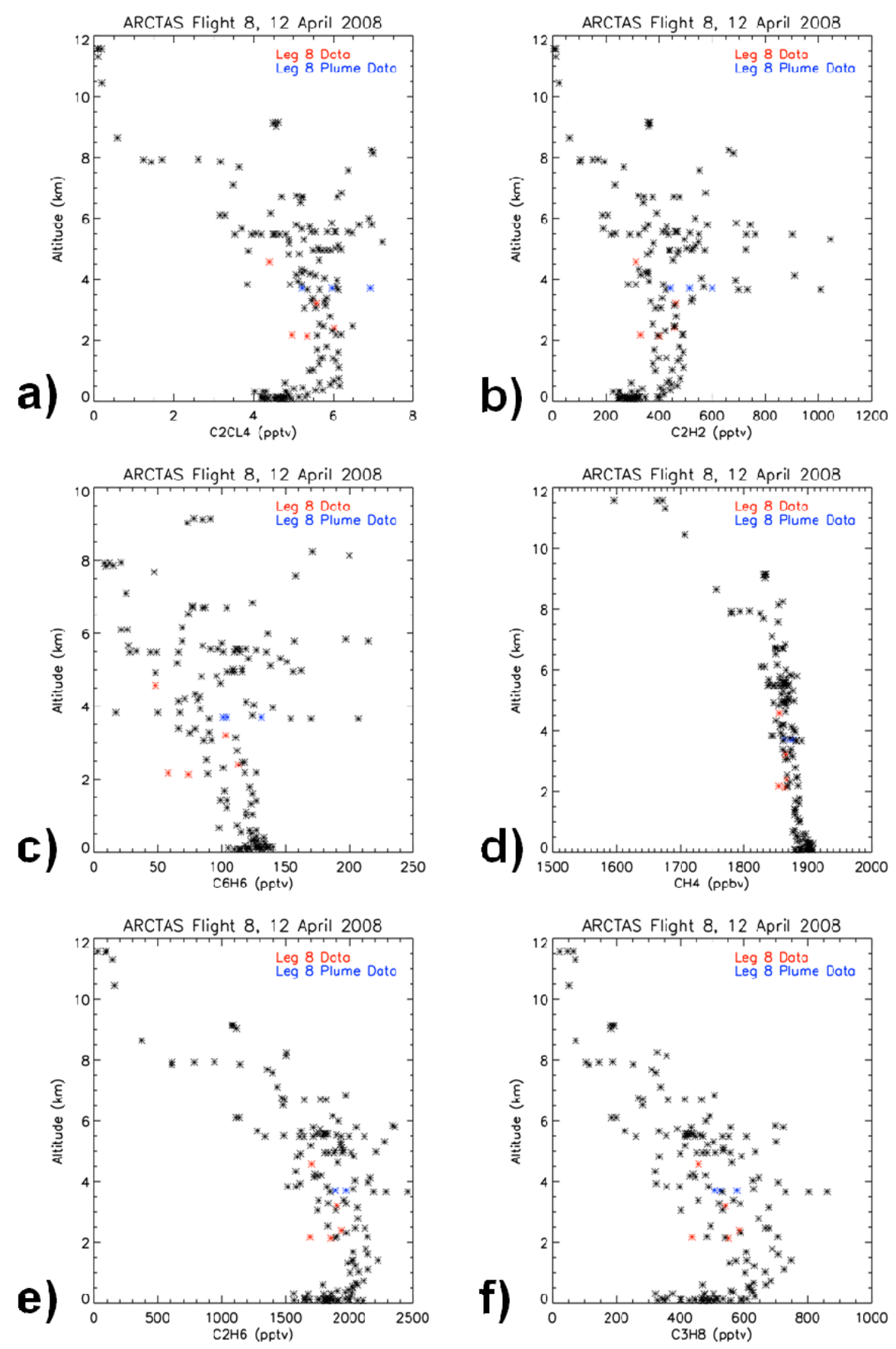

Fig. 14. Vertical distributions of data from flight 8 on 12 April 2008 for (a) $\mathrm{C}_{2} \mathrm{Cl}_{4}$, (b) $\mathrm{C}_{2} \mathrm{H}_{2}$, (c) $\mathrm{C}_{6} \mathrm{H}_{6}$, (d) $\mathrm{CH}_{4}$, (e) $\mathrm{C}_{2} \mathrm{H}_{6}$, and (f) $\mathrm{C}_{3} \mathrm{H}_{8}$. Red points are data from leg 8 . Blue points also are from leg 8 but represent the sampled plume. Black points represent the remaining legs of flight 8 .

emissions (Fig. 2f). When the trajectories are near Poland, 11 days prior to sampling (not shown), the flow becomes stagnant. Over the next two days, they drift eastward as a surface low develops over the Atlantic and moves onshore near Norway. The trajectories pass into the cyclone's warm sector where they begin to ascend 7 days prior to sampling (Fig. 17b). Once lofted into the upper troposphere, they are transported by the westerlies and are sampled by the DC- 8 . 


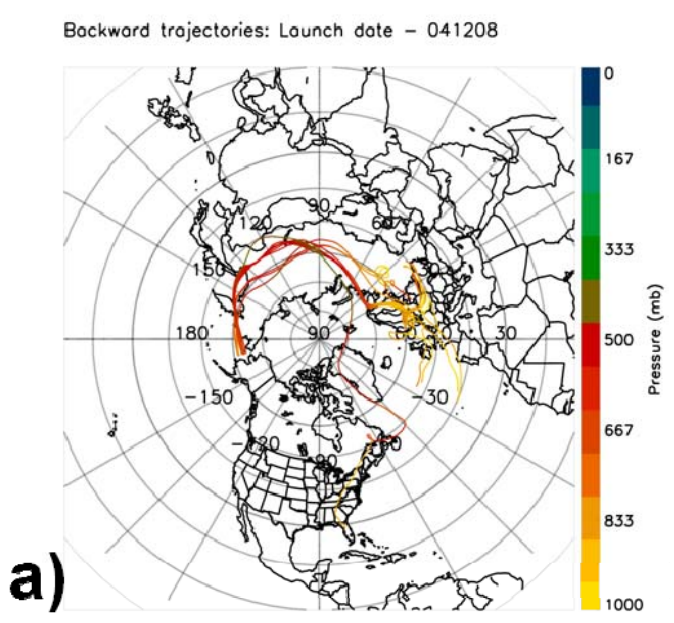

Bockword trojectories: Lounch dote -0.41208
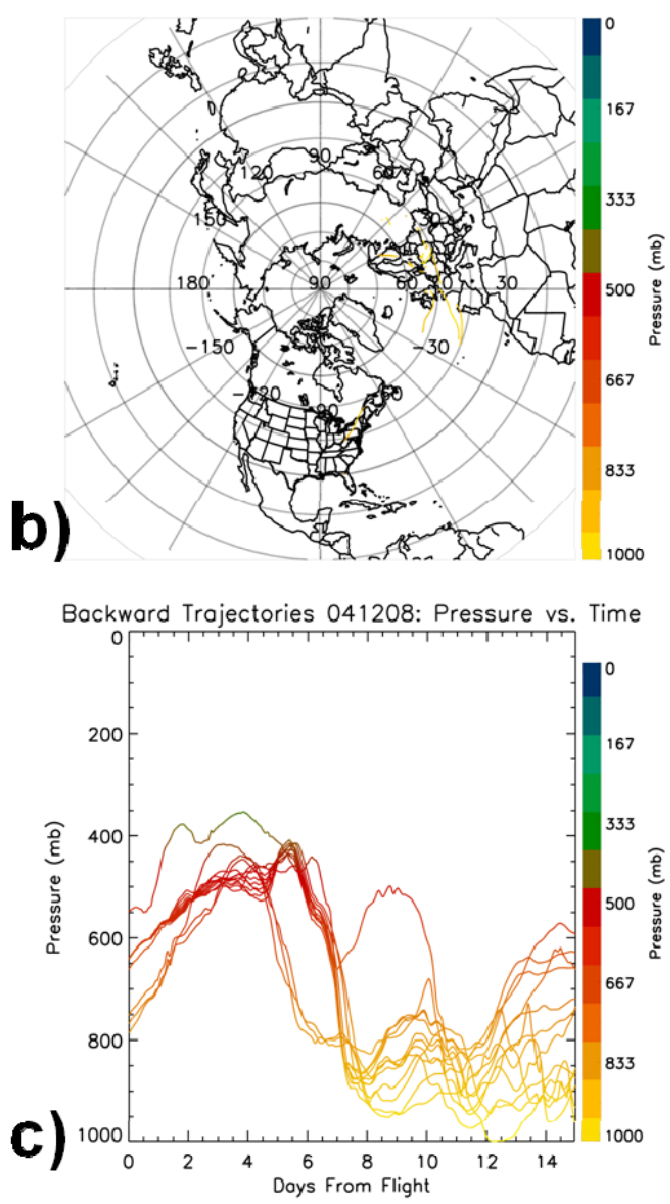

Fig. 15. As in Fig. 6, but for leg 8 on 12 April 2008.

Figure $15 \mathrm{c}$ presents the trajectories from Fig. $15 \mathrm{a}$ in a pressure versus time reference. Synoptic scale ascent is indicated between $\sim 6-8$ days prior to sampling. Similar to the previous cases, this is when the trajectories are in a cyclone's warm sector (Fig. 17b). Thus, potential WCB influences again were investigated using the criteria in Eckhardt et al. (2004).

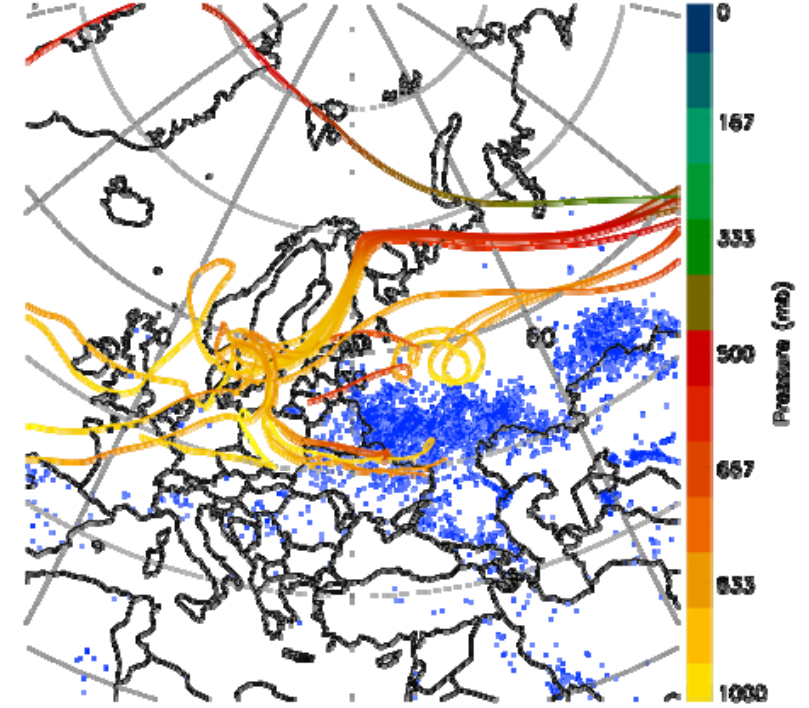

Fig. 16. Trajectories as in Fig. 15a plotted with FLAMBE data (blue dots) for the period 26 March-6 April 2008.

Ninety-two percent of the 13 trajectories examined satisfy the horizontal WCB criteria. The average tropopause height in the latitude belt $60-70^{\circ} \mathrm{N}$ was $9584 \mathrm{~m}$, with $60 \%$ of this value being $5751 \mathrm{~m}$. Only 1 of the 13 trajectories satisfies the $48 \mathrm{~h}$ ascent requirement. Similar to the previous case, if the criterion is decreased to $40 \%$ of the tropopause height $(3834 \mathrm{~m})$ during a $48 \mathrm{~h}$ period, $62 \%$ of the 13 trajectories meet the revised requirement. It is important to note that Figs. 15a and 16 show two separate groups of trajectories. The smaller group passes over Greenland and is not suspected to have undergone WCB processes. If we remove these 3 "stray" trajectories, $80 \%$ of the remainder satisfies the revised WCB requirements. Therefore, we believe it is probable that the trajectories' large scale ascent is due to a WCB.

In summary, these results strongly suggest that the DC8 sampled anthropogenic emissions along leg 8 of the 12 April 2008 flight. Vertical distributions showed enhancements in the purely anthropogenic tracer $\mathrm{C}_{2} \mathrm{Cl}_{4}$, as well as in natural gas tracers $\mathrm{CH}_{4}, \mathrm{C}_{2} \mathrm{H}_{6}$ and $\mathrm{C}_{3} \mathrm{H}_{8}$, determined to be of anthropogenic origins. The IC tracers $\mathrm{C}_{2} \mathrm{H}_{2}$ and $\mathrm{C}_{6} \mathrm{H}_{6}$ were shown to be of anthropogenic origin as well. Trajectory analysis showed that boundary layer encounters occurred across European locations with enhanced anthropogenic emissions (Fig. 2f). The leg 8 trajectories were lofted into the upper troposphere, most likely by a WCB, where they were subsequently sampled by the DC-8. Although the pathway taken by these trajectories was common during ARCTAS-A (Sect. 3.6), they did not enter the Arctic in the most common region (northern Europe/northeastern Russia, Fig. 13c). Instead, the trajectories entered the Arctic through one of the secondary regions. This secondary location, north of 

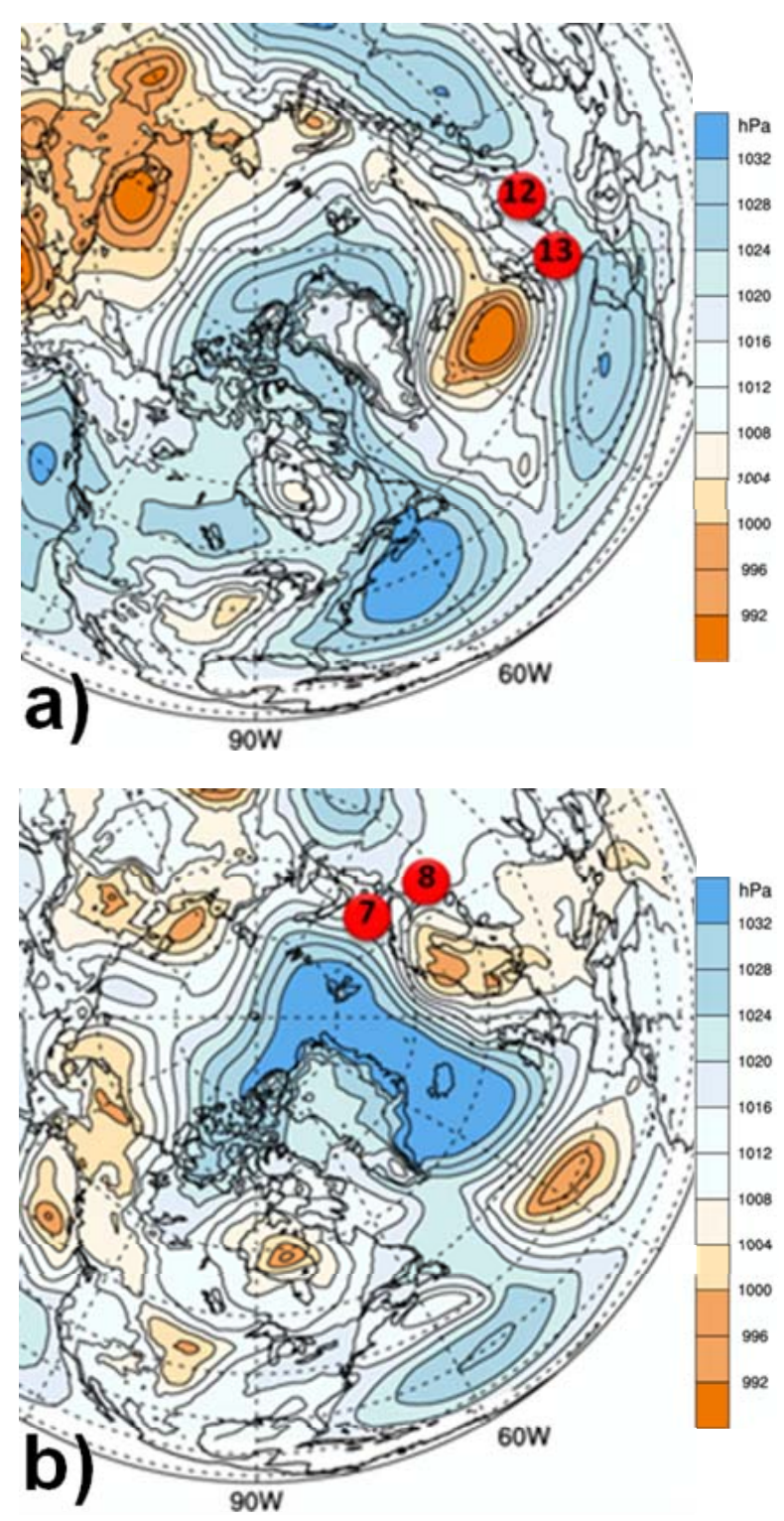

Fig. 17. Average location of trajectories comprising the largest group of trajectories in Fig. 15a (red circles) for (a) 12-13 days back from the flight and (b) 7-8 days back.

the Bering Strait is similar to that of emissions from Asia (Fig. 4c). Thus, emissions entering the Arctic in this area likely are a mixture of those from Asia and Europe, with the Asian emissions being more diluted than those from Europe.

\section{Summary and conclusions}

This study has examined the transport of anthropogenic emissions to the Arctic (defined as north of $70^{\circ} \mathrm{N}$ ) during NASA's ARCTAS field mission conducted during 2008 (Jacob et al., 2010). Our focus was the spring phase of ARCTAS
(ARCTAS-A) that occurred during April. Although biomass burning emissions dominated pollution transport to the Arctic during the study period (Warneke et al., 2009; Jacob et al., 2010), our goal was to document the Arctic transport and meteorology associated with anthropogenic emissions. Three source regions were studied, namely Asia, North America, and Europe. Meteorological data were obtained from high resolution simulations using the Weather Research and Forecasting (WRF) model.

Based on its chemical signature and backward trajectories, leg 5 from DC-8 flight 8 on 12 April 2008 was found to have sampled anthropogenic emissions originating from eastern Asia. Results showed enhancements of several key tracers (OCS, $\mathrm{CH}_{3} \mathrm{Cl}, 1,2-\mathrm{DCE}$, and $\mathrm{H}-1211$ ) that Barletta et al. (2009) have linked to eastern Asian anthropogenic emissions. Values of the purely anthropogenic species HCFC-22 and $\mathrm{C}_{2} \mathrm{Cl}_{4}$ also were enhanced along this leg. Carbonyl sulfide and $\mathrm{CH}_{3} \mathrm{Cl}$, two tracers that could have either biomass burning or anthropogenic origins, were highly correlated with the anthropogenic tracer $\mathrm{C}_{2} \mathrm{Cl}_{4}$, which led to the conclusion that both tracers had anthropogenic origins.

Fifteen day backward trajectories initiated along leg 5 were traced back to origins across eastern Asia in areas of anthropogenic emissions. Meteorological analyses highlighted the importance of synoptic scale cyclones and anticyclones in transporting the emissions. The results also illustrated the importance of a warm conveyor belt (WCB) in transporting the emissions to higher altitudes where they were sampled by the DC-8.

We determined mean transport characteristics of the ARCTAS-A period by investigating each day during the mission. Based on 15 day forward trajectories, Asian emissions during ARCTAS-A most commonly were transported eastward across the northern Pacific Ocean and then lofted into the upper levels. The coast of eastern Asia is a common location for the development of strong WCBs (Eckhardt et al., 2004), and we hypothesize that Asian transport to the Arctic often is facilitated by them. These emissions usually passed northward through the Bering Sea where they crossed $70^{\circ} \mathrm{N}$ latitude and entered the Arctic. Results showed that emissions from Asia most commonly entered the Arctic in the middle and upper levels during ARCTAS-A. Emissions that originated from higher latitudes across eastern Asia tended to arrive in the middle troposphere, while emissions originating at lower latitudes more commonly arrived in the upper troposphere.

Results showed that anthropogenic emissions from North America were sampled along leg 8 of DC- 8 flight 5 on 5 April 2008. Enhanced mixing ratios of several species, including two having strictly anthropogenic origins $\left(\mathrm{C}_{2} \mathrm{Cl}_{4}\right.$ and HCFC-22), were found along the leg. The incomplete combustion tracer $\mathrm{C}_{6} \mathrm{H}_{6}$ exhibited a good correlation with the purely anthropogenic tracer $\mathrm{C}_{2} \mathrm{Cl}_{4}$ and was determined to have anthropogenic origins. Similarly, two natural gas 
tracers $\left(\mathrm{C}_{2} \mathrm{H}_{6}\right.$ and $\left.\mathrm{C}_{3} \mathrm{H}_{8}\right)$ also correlated well with $\mathrm{C}_{2} \mathrm{Cl}_{4}$ indicating their origins were from anthropogenic sources.

Backward trajectories originating along leg 8 spent considerable time over North America. They were within the boundary layer over regions of known anthropogenic emissions, especially the US Northeast Corridor. Since WCBs frequently originate east of North America (Eckhardt et al., 2004), it was not surprising that a WCB likely was responsible for the vertical transport of these emissions to their sampling locations at the DC-8.

Emissions from North America generally traveled northeast across the far northwestern Atlantic and over the Labrador Sea. The emissions typically were lofted into the middle and upper troposphere along this path, with the ascent suspected to be commonly due to WCBs. Once lofted, the trajectories generally entered the Arctic in a region extending between western Nunavut, Canada and central Greenland. Similar to results for Asian anthropogenic emissions, trajectories that originated in the higher latitudes of North America typically entered the Arctic in the middle troposphere, while emissions from lower latitudes more frequently arrived in the upper troposphere.

Anthropogenic emissions from Europe were sampled along leg 8 of flight 8 on 12 April 2008. The purely anthropogenic tracer $\mathrm{C}_{2} \mathrm{Cl}_{4}$ was enhanced along this leg. Generally good correlations between $\mathrm{CH}_{4}, \mathrm{C}_{2} \mathrm{H}_{6}$ and $\mathrm{C}_{3} \mathrm{H}_{8}$ suggested an influence from an evaporative urban fossil fuel source such as natural gas and/or liquefied petroleum gas. These light alkanes were also well correlated with the purely anthropogenic tracer $\mathrm{C}_{2} \mathrm{Cl}_{4}$. Similarly, enhanced mixing ratios of $\mathrm{C}_{2} \mathrm{H}_{2}$ and $\mathrm{C}_{6} \mathrm{H}_{6}$ also were found along leg 8 , and since they were well correlated with $\mathrm{C}_{2} \mathrm{Cl}_{4}$, they were determined to have been from anthropogenic combustion sources as opposed to biomass burning.

Backward trajectories released along leg 8 indicated that the sampled air had passed within the boundary layer over eastern and western Europe. These are areas shown to have enhancements in anthropogenic emissions (Fig. 2f). Although WCBs seldom begin over Europe, a WCB was thought to be responsible for the trajectories' ascent from the lower to the upper troposphere where they were sampled by the DC-8. Although WCBs appear to be responsible for Arctic transport in all three of our case studies (Asia, North America, and Europe), that appears to be a coincidence. However, the lofting of mid-latitude air and resulting transport to the Arctic by WCBs are part of the three most common transport mechanisms to the Arctic that were mentioned by Stohl (2006) and in the Introduction.

Transport characteristics during ARCTAS-A revealed that European anthropogenic emissions frequently traveled northward out of Europe, entering the Arctic across northern Europe and northeastern Russia. Although this scenario was the most common method by which trajectories reached the Arctic, some emissions, including those from our case study, traveled eastward between $50-70^{\circ} \mathrm{N}$ to a wide range of Arc- tic entry locations along $70^{\circ} \mathrm{N}$. Unlike the Asian and North American domains, emissions that originated in the higher latitudes of Europe more frequently entered the Arctic in the lower troposphere, while emissions originating further south arrived in the middle and upper troposphere.

Although biomass burning emissions dominated Arctic transport during ARCTAS-A (e.g., Warneke et al., 2009; Jacob et al., 2010), the current results emphasize that anthropogenic emissions cannot be neglected. In the future, biomass burning emissions may become the dominant source of Arctic pollution due to increasing global temperatures that will promote enhanced numbers of wildfires.

Acknowledgements. The research at Florida State University was sponsored by the NASA Tropospheric Chemistry Program under Grant NNX0AH72G. The research at the University of California-Irvine was supported by NASA grant NNX09AB22G. We would like to express our sincere thanks to everyone who participated in the highly successful ARCTAS mission. Finally, we appreciate the helpful suggestions of three anonymous reviewers.

Edited by: A. Stohl

\section{References}

Anderson, B. E., Grant, W., Gregory, G., Browell, E., Collins Jr., J., Sachse, G., Bagwell, D., Hudgins, C., Blake, D., and Blake, N.: Aerosols from biomass burning over the south tropical Atlantic region: Distributions and impacts, J. Geophys Res., 101(D19), 24117-24138, 1996.

Aucott, M. L., McCulloch, A., Graedel, T. E., Kleiman, G., Midgley, P., and Li, Y.-F.: Anthropogenic emissions of trichloromethane (chloroform, $\mathrm{CHCl}_{3}$ ) and chlorodifluoromethane (HCFC-22): Reactive Chlorine Emissions Inventory, J. Geophys. Res., 104, 8405-8415, 1999.

Barletta, B., Meinardi, S., Simpson, I. J., Atlas, E. L., Beyersdorf, A. J., Baker, A. K., Blake, N. J., Yang, M., Midyett, J. R., Novak, B. J., McKeachie, R. J., Fuelberg, H. E., Sachse, G. W., Avery, M. A., Campos, T., Weinheimer, A. J., Rowland, F. S., and Blake, D. R.: Characterization of volatile organic compounds (VOCs) in Asian and north American pollution plumes during INTEX-B: identification of specific Chinese air mass tracers, Atmos. Chem. Phys., 9, 5371-5388, doi:10.5194/acp-9-5371-2009, 2009.

Barrie, L. A. and Hoff, R. M.: Five years of air chemistry observations in the Canadian Arctic, Atmos. Environ., 19, 1995-2010, 1985.

Barrie, L. A., Bottenheim, J. W., and Hart, W. R.: Polar Sunrise Experiment 1992 (PSE 1992): Preface, J. Geophys. Res., 99, 25313-25314, 1994.

Blake, N. J., Blake, D.R., Sive, B.C., Chen, T-Y., Rowland, F.S., Collins, Jr., J.E., Sachse, G.W., and Anderson, B.E.: Biomass burning emissions and vertical distribution of atmospheric methyl halide and other reduced carbon gases in the South Atlantic region, J. Geophys. Res., 101(D19), 2415124164, 1996.

Blake, N. J., Blake, D. R., Simpson, I. J., Meinardi, S., Swanson, A. L., Lopez, J. P., Katzenstein, A. S., Barletta, B., Shirai, T., Atlas, E., Sachse, G., Avery, M., Vay, S., Fuelberg, H. E., Kiley, 
C. M., Kita, K., and Rowland, F. S.: NMHCs and halocarbons in Asian continental outflow during the Transport and Chemical Evolution over the Pacific (TRACE-P) Field Campaign: Comparison With PEM-West B, J. Geophys. Res., 108(D20), 8806, doi:10.1029/2002JD003367, 2003.

Blake, N. J., Streets, D. G., Woo, J., Simpson, I. J., Green, J., Meinardi, S., Kita, K., Atlas, E., Fuelberg, H. E., Sachse, G., Avery, M. A., Vay, S. A., Talbot, R. W., Dibb, J. E., Bandy, A. R., Thornton, D. C., Rowland, F. S., and Blake, D. R.: Carbonyl sulfide and carbon disulfide: Large-scale distributions over the western Pacific and emissions from Asia during TRACE-P, J. Geophys. Res., 109, D15S05, doi:10.1029/2003JD004259, 2004.

Blake, D.: Whole air sampling (WAS) from the DC-8 aircraft during ARCTAS, 2008, available at: http://www.espo.nasa.gov/arctas/ docs/instruments/was.pdf, 2008.

Bradley, R. S., Keiming, F. T., and Diaz, H. F.: Climatology of surface-based inversions in the North American Arctic, J. Geophys. Res., 97, 15699-15712, 1992.

Butler, J. H., Montzka, S. A., Clarke, A. D., Lobert, J. M., and Elkins, J. W.: Growth and distribution of halons in the atmosphere, J. Geophys. Res., 103(D1), 1503-1511, 1998.

Carlson, T. N.: Speculations on the movement of polluted air to the Arctic, Atmos. Environ., 15, 1473-1477, 1981.

Carter, W. P. L.: Development of ozone reactivities for volatile organic compounds, JAPCA J. Air Waste Manag., 44, 881-899, 1994.

Curry, J. A.: On the formation of continental polar air, J. Atmos. Sci., 40, 2279-2292, 1983.

Curry, J. A.: The contribution of radiative cooling to the formation of cold-core anticyclone, J. Atmos. Sci., 44, 2575-2592, 1987.

Ding, A., Wang, T., Xue, L., Gao, J., Stohl, A., Lei, H., Jin, D., Ren, Y., Wang, X., Wei, X., Qi, Y., Liu, J., and Zhang, X.: Transport of north China air pollution by midlatitude cyclones: Case study of aircraft measurements in summer 2007, J. Geophys. Res., 114, D08304, doi:10.1029/2008JD011023, 2009.

Eckhardt, S., Stohl, A., Beirle, S., Spichtinger, N., James, P., Forster, C., Junker, C., Wagner, T., Platt, U., and Jennings, S. G.: The North Atlantic Oscillation controls air pollution transport to the Arctic, Atmos. Chem. Phys., 3, 1769-1778, doi:10.5194/acp3-1769-2003, 2003.

Eckhardt, S., Stohl, A., Wernli, H., James, P., Forster, C., and Spichtinger, N.: A 15-year climatology of warm conveyor belts, J. Climate, 17, 218-237, 2004.

Fraser, P. J., Oram, D. E., Reeves, C. E., Penkett, S. A., and McCulloch, A.: Southern hemispheric halon trends (1978-1998) and global halon emissions, J. Geophys. Res., 104(D13), 1598516000, 1999.

Fuelberg, H. E., Loring, Jr., R. O., Watson, M. V., Sinha, M. C., Pickering, K. E., Thompson, A. M., Sachse, G. W., Blake, D. R., and Schoeberl, M. R.: TRACE-A trajectory intercomparison 2. Isentropic and kinematic methods, J. Geophys. Res., 101, 23927-23939, 1996.

Fuelberg, H. E., Hannan, J. R., van Velthoven, P. F. J., Browell, E. V., Bieberbach, G. Jr., Knabb, R. D., Gregory, G. L., Pickering, K. E., and Selkirk, H. B.: A meteorological overview of the SONEX period, J. Geophys. Res., 105, 3633-3651, 2000.

Fuelberg, H. E., Harrigan, D. L., and Sessions, W.: A meteorological overview of the ARCTAS 2008 mission, Atmos. Chem. Phys., 10, 817-842, doi:10.5194/acp-10-817-2010, 2010.
Hileman, B.: Arctic Haze, Environ. Sci. Technol., 17(6), 232-236, doi:10.1021/es00112a602, 1983.

Hoff, R. M.: Vertical structure of Arctic Haze observed by lidar, J. Appl. Meteor., 27, 125-139, 1987.

Iverson, T.: On the atmospheric transport of pollution to the Arctic, Geophys. Res. Lett., 11, 457-460, 1984.

Jacob, D. J., Crawford, J. H., Maring, H., Clarke, A. D., Dibb, J. E., Emmons, L. K., Ferrare, R. A., Hostetler, C. A., Russell, P. B., Singh, H. B., Thompson, A. M., Shaw, G. E., McCauley, E., Pederson, J. R., and Fisher, J. A.: The Arctic Research of the Composition of the Troposphere from Aircraft and Satellites (ARCTAS) mission: design, execution, and first results, Atmos. Chem. Phys., 10, 5191-5212, doi:10.5194/acp-10-5191-2010, 2010.

Kasischke, E. S., Hyer, E. J., Novelli, P. C., Bruhwiler, L. P., French, N. H. F., Sukhinin, A. I., Hewson, J. H., and Stocks, B. J.: Influences of boreal fire emissions on Northern Hemisphere atmospheric carbon and carbon monoxide, Global Biogeochem. Cy., 19, GB1012, doi:10.1029/2004GB002300, 2005.

Katzenstein, A. S., Doezema, L. A., Simpson, I. J., Blake, D. R., and Rowland, F. S.: Extensive regional atmospheric hydrocarbon pollution in the southwestern United States, Proc. Nat. Acad. Sciences, 100, 11, 975-11, 979, 2003.

Kettle, A. J., Kuhn, U., von Hobe, M., Kesselmeier, J., and Andreae, M. O.: Global budget of carbonyl sulfide: Temporal and spatial variations of the dominant sources and sinks, J. Geophys. Res., 107(D22), 4658, doi:10.1029/2002JD002187, 2002.

Klonecki, A., Hess, P., Emmons, L., Smith, L., and Orlando, J.: Seasonal changes in the transport of pollutants into the Arctic troposphere-model study, J. Geophys. Res., 8367, doi:1029/2002JD002199, 2003.

Kondo, Y., Sahu, L., Moteki, N., Takegawa, N., Matsui, H., Zhao, Y., Vay, S., Diskin, G. S., Anderson, B., Wisthaler, A., Jimenez, J. L., Fuelberg, H. E., Huey, G., Weinheimer, A. J., and Brune, W. H.: Emissions of black carbon and organic aerosols from forest fires in Canada and Russia in 2008, J. Geophys. Res., 116, D08204, doi:10.1029/2010JD015152, 2011.

Law, K. S. and Stohl, A.: Arctic air pollution: Origins and impacts, Science, 315, 1537-1540, doi:10.1126/science.1137695, 2007.

Lee, B. H., Munger, J. W., Wofsy, S. C., and Goldstein, A. H.: Anthropogenic emissions of nonmethane hydrocarbons in the northeastern United States: Measured seasonal variations from 1992-1996 and 1999-2001, J. Geophys. Res., 111, D20307, doi:10.1029/2005JD006172, 2006.

Li, S. M. and Barrie, L. A.: Biogenic sulphur aerosols in the Arctic troposphere, 1. Contributions to sulphate, J. Geophys. Res., 98(D11), 20613-20622, 1993.

Martin, B. D., Fuelberg, H. E., Blake, N. J., Crawford, J. H., Logan, J. A., Blake, D. R., and Sachse, G. W.: Long range transport of Asian outflow to the equatorial Pacific, J. Geophys. Res., 108(D2), 8322, doi:10.1029/2001JD001418, 2002.

Matsui, H., Kondo, Y., Moteki, N., Takegawa, N., Sahu, L. K., Zhao, Y., Fuelberg, H. E., Sessions, W., Diskin, G., Blake, D. R., and Wisthaler, A.: Seasonal variation of the transport of black carbon aerosol from the Asian continent to the Arctic during the ARCTAS aircraft campaign, J. Geophys. Res., 116, D05202, doi:10.1029/2010JD015067, 2011.

Meyer, F. G., Curry, J. A., Brock, C. A., and Radke, L. F.: Springtime visibility in the Arctic, J. Appl. Meteor., 30, 342-357, 1990.

Mitchell, J. M. Jr.: Visual range in the polar regions with particular 
reference to the Alaskan Arctic, J. Clim. Appl. Meteor., 23, 916928, 1957.

Montzka, S. A., Hall, B. D., and Elkins, J. A.: Accelerated increases observed for hydrochlorofluorocarbons since 2004 in the global atmosphere, Geophys. Res. Lett., 36, L03804, doi:10.1029/2008GL036475, 2009.

Oltmans, S. J., Lefohn, A. S., Harris, J. M., Tarasick, D. W., Thompson, A. M., Wernli, H., Johnson, B. J., Davies, J., Novelli, P. C., Montzka, S. A., Sweeney, C., Patrick, L. A., Jefferson, A., Dann, T., Ray, J. D., and Shapiro, M.: Enhanced ozone over western North America from biomass burning in Eurasia during April 2008 as seen in surface and profile observations,, Atmos. Environ., 44, 35, 4497-4509, doi:10.1016/j.atmosenv.2010.07.004, 2010.

Quinn, P. K., Miller, T. L., Bates, T. S., Ogren, J. A., Andrews, E., and Shaw, G. E.: A three-year record of simultaneously measured aerosol chemical and optical properties at Barrow, Alaska. J. Geophys. Res., 107(D11), doi:10.1029/2001JD001248, 2002.

Raatz, W. E. and Shaw, G. E.: Long-range tropospheric transport of pollution aerosols in the Alaskan Arctic, J. Clim. Appl. Meteor., 23, 1052-1064, 1984.

Raatz, W. E.: The climatology and meteorology of Arctic air pollution, in: Pollution of the Arctic Atmosphere, edited by: Sturges, W. T., Elsevier, New York, 13-42, 1991.

Reid, J., Hyer, E. J., Prins, E. M., Westphal, D. L., Zhang, J., Wang, J., Christopher, S. A., Curtis, C. A., Schmidt, C. A., Eleuterio, D. P., Richardson, K. A., and Hoffman, J. P.: Global Monitoring and Forecasting of Biomass Burning Smoke: Description of and Lessons From the Fire Locating and Modeling of Burning Emissions (FLAMBE) Program, IEEE J. Sel. Top. Appl., 2, 2009.

Rinke, A., Dethloff, K., and Fortmann, M.: Regional climate effects of Arctic Haze, Geophys. Res. Lett., 31, L16202, doi:10.1029/2004GL020318, 2004.

Russo, R., Talbot, R. W., Dibb, J. E., Scheuer, E., Seid, G., Jordan, C. E., Fuelberg, H. E., Sachse, G. W., Avery, M. A., Vay, S. A., Blake, D. R., Blake, N. J., Atlas, E., Fried, A., Sandholm, S. T., Tan, D., Singh, H. B., Snow, J., and Heikes, B. G.: Chemical composition of Asian continental outflow over the western Pacific: Results from Transport and Chemical Evolution over the Pacific (TRACE-P), J. Geophys. Res., 108(D20), 8804, doi:10.1029/2002JD003184, 2003.

Russo, R. S., Zhou, Y., White, M. L., Mao, H., Talbot, R., and Sive, B. C.: Multi-year (2004-2008) record of nonmethane hydrocarbons and halocarbons in New England: seasonal variations and regional sources, Atmos. Chem. Phys., 10, 4909-4929, doi:10.5194/acp-10-4909-2010, 2010.

Sachse, G. W., Hill, G. F., Wade, L. O., and Perry, M. G.: Fastresponse, highprecision carbon monoxide sensor using a tunable diode laser absorption technique, J. Geophys. Res., 92, 20712081, 1987.

Sachse, G. W., Harriss, R. C., Fishman, J., Hill, G.F., and Cahoon, D.R.: Carbon monoxide over the Amazon basin during the 1985 dry season, J. Geophys. Res., 93, 1422-1430, 1988.

Schnell, R. C.: Arctic haze and the Arctic gas aerosol sampling program (AGASP), Geophys. Res. Lett., 11, 361-364, 1984.

Shaw, G. E.: Evidence for a central Eurasian source area of Arctic haze in Alaska, Nature, 299, 815-818, 1983.

Shaw, G. E.: The Arctic haze phenomenon, B. Am. Meteor. Soc., 76, 2403-2413, 1995.
Simpson, I. J., Meinardi, S., Blake, N. J., Rowland, F. S., and Blake, D. R.: Long-term decrease in the global atmospheric burden of tetrachloroethene $\left(\mathrm{C}_{2} \mathrm{Cl}_{4}\right)$, Geophys. Res. Lett., doi:10.1029/2003GL019351, 2004.

Simpson, I. J., Blake, N. J., Barletta, B., Diskin, G. S., Fuelberg, H. E., Gorham, K., Huey, L. G., Meinardi, S., Rowland, F. S., Vay, S. A., Weinheimer, A. J., Yang, M., and Blake, D. R.: Characterization of trace gases measured over Alberta oil sands mining operations: 76 speciated $\mathrm{C}_{2}-\mathrm{C}_{10}$ volatile organic compounds (VOCs), $\mathrm{CO}_{2}, \mathrm{CH}_{4}, \mathrm{CO}, \mathrm{NO}, \mathrm{NO}_{2}, \mathrm{NO}_{y}, \mathrm{O}_{3}$ and $\mathrm{SO}_{2}$, Atmos. Chem. Phys., 10, 11931-11954, doi:10.5194/acp10-11931-2010, 2010.

Singh, H. B., Anderson, B. E., Brune, W. H., Cai, C., Crawford, J. H., Cohen, R. C., Czech, E. P., Emmons, L., Fuelberg, H. E., Huey, G., Jacob, D. J., Jimenez, J. L., Kondo, Y., Kaduwela, A., Mao, J., Olson, J. R., Sachse, G. W., Vay, S. A., Weinheimer, A., Wennberg, P. O., and Wisthaler, A.: Pollution influences on atmospheric composition and chemistry at high northern latitudes: Boreal and California forest fire emissions, Atmos. Environ., 44, 4553-4564, 2010.

Skamarock, W. C., Klemp, J. B., Dudhia, J., Gill, D. O. Barker, D. M., Duda, M. G., Huang, X., Wang, W., and Powers, J. G.: A description of the Advanced Research WRF version 3. NCAR Tech. Note NCAR/TN-475+STR, 113 pp., 2008.

Stohl, A.: A 1-year Lagrangian "climatology" of airstreams in the Northern Hemisphere troposphere and lowermost stratosphere, J. Geophys. Res., 106(D7), 7263-7279, 2001.

Stohl, A.: Characteristics of atmospheric transport into the Arctic troposphere, J. Geophys Res., D11306, doi:1029/2005JD006888, 2006.

Stohl, A., Wotawa, G., Seibert, P., and Kromp-Kolb, H.: Interpolation errors in wind fields as a function of spatial and temporal resolution and their impact on different types of kinematic trajectories, J. Appl. Meteor., 34, 2149-2165, 1995.

Stohl, A., Hittenberger, M., and Wotawa, B.: Validation of the Lagrangian particle dispersion model FLEXPART against large scale tracer experiments, Atmos. Environ., 32, 4245-4264, 1998.

Stohl, A., Forster, C., Frank, A., Seibert, P., and Wotawa, G.: Technical note: The Lagrangian particle dispersion model FLEXPART version 6.2, Atmos. Chem. Phys., 5, 2461-2474, doi:10.5194/acp-5-2461-2005, 2005.

Stohl, A., Eckhardt, S., Forster, C., James, P., and Spichtinger, $\mathrm{N}$. : On the pathways and timescales of intercontinental air pollution transport, J. Geophys. Res. 107(D23), 4684, doi:10.1029/2001JD001396, 2002.

Streets, D. G., Bond, T. C., Carmichael, G. R., Fernandes, S. D., Fu, Q., He, D., Klimont, Z., Nelson, S. M., Tsai, N. Y., Wang, M. Q., Woo, J. H., and Yarber, K. F.: An inventory of gaseous and primary aerosol emissions in Asia in the year 2000, J. Geophys. Res., 108(D21), 8809, doi:10.1029/2002JD003093, 2003.

Warneke, C., Bahreini, R., Brioude, J., Brock, C. A., de Gouw, J. A., Fahey, D. W., Froyd, K. D., Holloway, J. S., Middlebrook, A., Miller, L., Montzka, S., Murphy, D. M., Peischl, J., Ryerson, T. B., Schwarz, J. P., Spackman, J. R., and Veres, P.: Biomass burning in Siberia and Kazakhstan as an important source for haze over the Alaskan Arctic in April 2008, Geophys. Res. Lett., 36, L02813, doi:10.1029/2008GL036194, 2009.

Warneke, C., McKeen, S. A., de Gouw, J. A., Goldan, P. D., Kuster, W. C., Holloway, J. S., Williams, E. J., Lerner, B. M., 
Parrish, D. D., Trainer, M., Fehsenfeld, F. C., Kato, S., Atlas, E. L., Baker, A., and Blake, D. R.: Determination of urban volatile organic compound emission ratios and comparison with an emissions database, J. Geophys. Res., 112, D10S47, doi:10.1029/2006JD007930, 2007.

Warneke, C., Froyd, K. D., Brioude, J., Bahreini, R., Brock, C. A., Cozic, J., de Gouw, J. A., Fahey, D. W., Ferrare, R., Holloway, J. S., Middlebrook, A. M., Miller, L., Montzka, S., Schwarz, J. P., Sodemann, H., Spackman, J. R., and Stohl, A.: An important contribution to springtime Arctic aerosol from biomass burning in Russia, Geophys. Res. Lett., 37, L01801, doi:10.1029/2009GL041816, 2010.
Watts, S. F.: The mass budget of carbonyl sulfide, dimethyl sulfide, carbon disulfide, and hydrogen sulfide, Atmos. Environ., 34, 761-779, 2000.

Wotton, B. M., Nock, C. A., and Flannigan, M. D., Forest fire occurrence and climate change in Canada, Intl. J. Wildland Fire, 19 (3), 253-271, 2010.

Xiao, Y., Logan, J. A., Jacob, D. J., Hudman, R. C., Yantosca, R., and Blake, D. R.: Global budget of ethane and regional constraints on US sources, J. Geophys. Res., 113, D21306, doi:10.1029/2007JD009415, 2008. 